\title{
CONTEXTUALIZACIÓN E ICONOGRAFÍA DE LAS TABLETAS PSICOTRÓPICAS TIWANAKU DE SAN PEDRO DE ATACAMA
}

\author{
CONTEXTUALIZATION AND ICONOGRAPHY OF TIWANAKU PSYCOTROPIC \\ TABLETS FROM SAN PEDRO DE ATACAMA
}

\author{
Agustín Llagostera ${ }^{1}$
}

\begin{abstract}
Este artículo entrega una exhaustiva e individualizada descripción y clasificación (textual y gráfica) de 39 tabletas tiwanaku procedentes de contextos funerarios excavados en San Pedro de Atacama. Se realiza un análisis de dichos contextos y de los sitios en los cuales estas tabletas se encuentran insertas; se comparan los componentes iconográficos entre los ejemplares por categorías y por sitios; se intenta acotar la cronología y definir una secuencia para estos artefactos; se contrasta la iconografía con los antecedentes conocidos para la iconografía tiwanaku nuclear y se discuten los mecanismos a través de los cuales estas tabletas pudieron llegar a San Pedro de Atacama.

Los resultados indican que las tabletas de filiación tiwanaku representan un bajo porcentaje (17,5\%), demostrando que la mayor cantidad de tabletas, contemporáneas con el evento tiwanaku $(82,5 \%)$, no estaría relacionada con la entidad altiplánica. Por otro lado, la diversidad de atributos tanto en las representaciones como en los elementos secundarios hace de cada una de las tabletas tiwanaku un ejemplar prácticamente único, y su distribución entre los sitios arqueológicos resulta ser aleatoria; no se visualiza un patrón que refleje coherencia en el manejo espacial de estos artefactos. De esta heterogeneidad, anarquía y baja representatividad se deduce que las tabletas tiwanaku, además de ser importaciones foráneas, no provienen de un único lugar de origen sino de diversas procedencias. Estos artefactos se encuentran insertos en contextos locales y un significativo número de sus portadores exhibe también artefactos de estatus (hachas, mazos u objetos metálicos), por lo que estas personas habrían ostentado un cierto rango en la comunidad.
\end{abstract}

Palabras claves: arqueología de San Pedro de Atacama, Tiwanaku, complejo alucinógeno, iconografía precolombina.

This article presents an exhaustive, individualized description, and classification (textual and graphic) of 39 Tiwanaku tablets excavated from funerary contexts in San Pedro de Atacama. A textual context analysis is conducted from sites in which tablets have been recovered; iconographic components are compared between specimens by category and by sites. The chronology is examined and a sequence for these artifacts is defined. The iconography is contrasted wit the care Tiwanaku iconography and mechanisms are discussed as to how the tablets could have come to San Pedro de Atacama.

The results indicate that a low percentage (17.5\%) of the tablets is affiliated with Tiwanaku demonstrating that the majority of the tablets, contemporary with Tiwanaku (82.5\%), were not connected to the altiplano polity. However, the diversity of the attributes in their representations, such as secondary elements, make each one of the Tiwanaku tablets practically unique examples, and the distribution between the archaeological sites turn out to be random. No pattern can be observed that reflects coherence in the spatial management of the artifacts. From this heterogeneity, anarchy, and poor representative nature it can be deduced that the Tiwanaku tablets, besides being foreign imports, do not originate from one single place of origin. These artifacts are brought into local contexts and a significant number of their bearers also exhibit artifacts of status (axes, mallets or metal objects) because these persons display a certain status in the community.

Key words: Archaeology of San Pedro de Atacama, Tiwanaku, snuffs complex, precolombian iconography.

El problema de las tabletas para alucinógenos con iconografía tiwanaku en San Pedro de Atacama (en adelante SPA) no sólo toca el tema de la presencia de Tiwanaku en esta localidad, sino que SPA resulta ser el único lugar en los Andes donde se ha conservado un relativamente alto número de tabletas de dicha entidad. Por esto es importante profundizar en su contextualización, ya que sólo aquí se puede tener la oportunidad de conocer con detalle los ámbitos, circunstancias y roles que estos artefactos tuvieron. Según Torres $(2001)^{1}$, hasta el momento se registra un total de 84 tabletas reconocidas como tiwanakotas en los Andes de las cuales $63(75 \%)$ fueron encontradas en SPA.

\footnotetext{
1 Instituto de Investigaciones Arqueológicas y Museo, Universidad Católica del Norte, San Pedro de Atacama, Chile. allagost@ucn.cl
} 
En el presente trabajo, a través del análisis de la iconografía tiwanaku en la parafernalia psicotrópica de SPA, se aportan antecedentes para entender la presencia de objetos tiwanakotas en esta localidad y, detrás de ellos, comprender la forma de interacción entre estas dos localidades. Si las tabletas psicotrópicas se integraron al sistema de intercambio no pudieron hacerlo al mismo nivel, ni en los mismos contextos, que objetos como las vasijas de cerámica o porciones de papas, lana o productos del mar. Las tabletas no son simplemente vasijas o recipientes; por la imaginería que se asocia con ellas, están directamente relacionadas con la cosmovisión. En consecuencia, tienen una connotación sagrada, son verdaderos templos portátiles. Ellas están relacionadas con el nivel ideológico de la sociedad y no pueden haber entrado a un esquema de transacción bajo los mismos cánones de equivalencia que los artefactos de uso doméstico o los productos de subsistencia.

Aunque ya se han realizado análisis sobre la iconografía tiwanaku en tabletas, incluyendo las de SPA (Llagostera 1995, 2001; Llagostera et al. 1988; Torres 1984, 1998, 2001), consideramos que el tema no ha sido agotado, sobre todo en la necesidad de contextualizar dicha iconografía. A eso apunta este trabajo y para ello se hace necesario, previamente, utilizar la iconografía como una manera de identificar y caracterizar cada una de las piezas que serán contextualizadas. Hasta ahora las tabletas tiwanaku de SPA han sido tratadas en términos generales y no existe una descripción pormenorizada de ellas, ni un análisis de los contextos a los que se encuentran asociadas. La escasa información que acompaña a las tabletas tiwanakotas recuperadas del centro mismo de Tiwanaku hace aún más valioso el conocimiento que se puede tener de las tabletas de dicha filiación halladas en SPA.

\section{Antecedentes de las Prácticas Psicotrópicas en San Pedro de Atacama}

Las tabletas para inhalación de alucinógenos están presentes en SPA desde mucho antes de la interacción con Tiwanaku (Llagostera 1995, 1996). La tradición psicotrópica se remonta a los tempranos momentos de la etapa agropastoralista, donde se registran grandes pipas de cerámica. Sin embargo, es en las llamadas "tabletas para rapé" donde el psicotropismo se hace indiscutible. La colección de tabletas para alucinógenos del Museo Arqueológico “R.P. Gustavo Le Paige S.J." de SPA asciende a 465 ejemplares y su asociación con alucinógenos las relaciona con el "cebil" (Anadenanthera colubrina). Esto en consideración al hallazgo de bufotenina en muestras de sustancias asociadas con tabletas en SPA, posiblemente obtenida de una planta del género Anadenanthera (Torres et al. 1991).

Inicialmente, las tabletas fueron traídas de otras partes. Sin embargo, a medida que transcurrió el tiempo, los atacameños asimilaron y se hicieron expertos en el ritualismo psicoactivo, comenzando a modelar sus propios recipientes para alucinógenos con imágenes de su cosmovisión. En consecuencia, las primeras tabletas propiamente atacameñas comenzaron a ser confeccionadas ya avanzado el Agropastoralismo Temprano (Fase Quitor: 400-700 d.C.) y muestran, predominantemente, la figura humana $y$, con menor frecuencia, la figura del felino (Llagostera 2001).

En el período Medio (Fase Coyo 700-950 d.C.), cuando se hace manifiesta la influencia Tiwanaku, se hacen presentes en SPA tabletas para alucinógenos que replican la iconografía de artefactos propios de la cultura Tiwanaku. Estas tabletas, que son de una muy elaborada expresión artística, se caracterizan por un marcado barroquismo dado por una densa iconografía secundaria que entorna la figura principal.

Es necesario resaltar que en el período Medio no todas las tabletas se adscriben al estilo tiwanakota; hay una buena proporción de tabletas que no se asimilan a dicho estilo aunque, igualmente, pueden ser de panel plano o con figuras tridimensionales.

En un primer trabajo contextual sobre el complejo psicotrópico, en un sitio arqueológico de SPA, Llagostera y colaboradores (1988) concluyeron que los individuos de Solcor 3 hallados en sus tumbas asociados con objetos para inhalar alucinógenos presentan varios atributos culturales similares a los del resto de la población, además de otros, que los hacen diferir de los patrones comunes. Las distancias biológicas indican para ellos una raigambre compartida con la población local y la deformación craneana, tomada como indicador étnico, confirmaría su filiación a la comunidad atacameña. Estos dos últimos registros señalan que los portadores de implementos psicotrópicos son miembros de la población que, por determinados méritos o designios, han adquirido la condición de chama- 
nes, asumiendo que las prácticas con alucinógenos eran prerrogativas de estos personajes. Los investigadores agregan que es notoria la frecuencia con que los portadores de tabletas aparecen asociados con el tráfico caravanero trasandino (objetos foráneos), con evidencias de un moderado estatus social (ajuares relevantes) y también con símbolos de poder (mazos o hachas). La relación con las prácticas psicotrópicas parecería constituir prerrequisito para configurar las jefaturas en SPA, con mayor notoriedad, en el período de más intensa influencia altiplánica.

\section{Iconografía Tiwanaku y Morfología de las Tabletas}

La iconografía tiwanakota es fácilmente identificable por las expresiones que de ella se tiene en las esculturas líticas existentes en Tiwanaku mismo y por la alfarería procedente de ese lugar, siendo esos los materiales que mayormente se han conservado de dicha cultura.

Las representaciones en las tabletas tiwanakotas de SPA pueden ser grabadas en paneles planos o esculpidos tridimensionalmente; en cualquiera de los casos, siempre está presente alguno de los 38 elementos señalados por Torres (1984), lo que delata su filiación. Entre estos elementos adicionales, que llamaremos iconografía complementaria o secundaria, destacan especialmente las pequeñas cabezas antropo y zoomorfas. Aunque todas ellas fueron diseñadas en perfil, las dos primeras pueden, a veces, aparecer de frente. Ellas se ubican preferentemente adheridas a tocados, cabelleras, túnicas o faldellines, cetros y pedestales. Hay otros aditamentos mayormente presentes en los tocados que en sus diversas estilizadas expresiones podrían representar elementos fitomorfos; otros, especialmente tripartitos, parecieran estar asociados con plumas, a modo de penachos o colas de ave. En un caso, en el tocado se ha integrado una pierna humana y, en otro, un cuerpo humano sin cabeza. Sin duda, lo que estamos llamando tocado es el componente más complejo y el que aparece investido de mayor simbolismo en la iconografía tiwanaku.

Las tabletas planas del más clásico estilo Tiwanaku son bastante rígidas en su canon de presentación iconográfica. Prácticamente hay tres patrones que se repiten en los paneles. Uno, está reservado solamente para la figura humana y la representa en posición frontal; otro, muestra una figura de perfil mirando hacia arriba y portando un cetro; un tercero, representa un camélido de perfil. Cada uno de estos patrones puede presentar variaciones, pero sin alterar sustancialmente los módulos canónicos que componen el panel en cada uno de los tres casos. A su vez, los módulos están estructurados por componentes del propio personaje o por elementos que se combinan o repiten armoniosamente, dando un aspecto recargado a la composición general.

El personaje antropomorfo frontal pareciera corresponder a una forma bidimensional de las esculturas monolíticas. Se presenta en dos variantes: una con manos sobre el pecho y, otra, con brazos expandidos hacia los lados y con cetros. Las primeras se identificarían con los monolitos columnares y las otras, con el personaje central de la Puerta del Sol. En las tabletas, ambas versiones se hacen presentes tanto en un esquema compacto de tres o cuatro franjas horizontales que delimitan las partes de la figura principal (tocado, cabeza, cuerpo y extremidades inferiores), en tanto que la segunda se manifiesta también en un estilo que podríamos llamar distendido, no tan recargado. Entre los elementos que componen el tocado es frecuente encontrar una forma que ha sido considerada como la representación del cebil (Knobloch 2000).

Los personajes antropomorfos de perfil se muestran en posición genuflexa, normalmente mirando hacia arriba; algunas veces pueden presentar una prominente nariz y dentadura felínica; en otras, toda su cabeza es de felino. La figura del Sacrificador asume representativamente este canon como una de sus estereotipadas expresiones. Es interesante constatar que las imágenes de perfil, cualquiera entidad que representen, siempre se muestran mirando hacia el lado izquierdo del observador. Esta posición podría estar relacionada con el hecho de que en las tradiciones andinas el lado izquierdo se identifica con la muerte y con el espacio cósmico del "más allá"; en suma, con aquella dimensión donde radican los misterios y las entidades sobrenaturales.

El camélido, en el estereotipo bidimensional, también se enfrenta al lado izquierdo, lleva tocado y capa, y su aspecto recuerda la forma de las vasijas sahumadoras, típicas en la alfarería Tiwanaku. Siempre está cargando en su grupa un bulto constituido por un rostro antropomorfo que podría representar alguna entidad celeste. De esta entidad salen ramificaciones, las que, en algunos casos, tienen características fitomorfas, diferentes a las de 
los personajes frontales, pero similares a motivos que aparecen en Chavín y que Cordy-Collins (1979) piensa que representan el algodón. A veces, en las terminaciones de las cintas que surgen del ojo y del talón de ese animal, puede verse un motivo semejante al que Yacovleff y Herrera (1934-35) identifican como maíz en la iconografía precolombina peruana. La asociación de este camélido con vegetales no sería extraña, ya que en la cosmovisión andina el ciclo agrícola tenía una estrecha relación con los camélidos, como la constelación de la llama que señalaba la época del cultivo (Urton 1981).

En SPA se conocen seis tabletas tiwanakotas en las cuales la imagen principal ha sido tallada en tres dimensiones. Cuatro de ellas se desarrollan en continuidad con el plano de la tableta: dos sacrificadores, un personaje monolítico y un cóndor. En ellas, los personajes tridimensionales aparecen posados sobre el borde distal del artefacto, en tanto que el pedestal escalerado, que sirve de soporte a todas las figuras tiwanakotas, está grabado en la porción que se conserva del panel plano. Otras dos, un humano y un felino, aparecen, una sentada y la otra erguida, sobre el borde del panel plano. La representación de la persona sentada se repite en una tableta existente en el American Museum of Natural History de New York, cuya procedencia sería SPA (Torres 1987, Lám. 97).

Tabletas con iconografía tiwanaku en SPA se registran para los sitios: Coyo Oriente, Quitor 2, Quitor 5, Quitor 6, Séquitor Alambrado Oriente y Solcor 3 (Figura 1).

\section{Tipología de Imágenes y Representaciones Tiwanaku}

De las 39 tabletas con iconografía Tiwanaku de SPA, éstas se ordenan de acuerdo a la imagen principal que ellas representan, asimilándolas a entidades o componentes biomorfos (figuras humanas, cabezas o rostros humanos, felinos, falcónidas, camélidos y entes híbridos entre humanos y animales); cuando ha sido atingente, se ha destacado algún atributo relevante (p. ej. con brazos extendidos portando cetros, imágenes simples o dobles, etc.). Seguidamente nos referimos al modo en que dichas imágenes son representadas, ya sea en superficie plana, en volumen o en una combinación de ambas (mixta), especificando, en caso de las representaciones planimétricas, si la imagen se muestra en vista frontal o de perfil. Por último, se hace referencia a lo que sería el patrón: compacto, distendido, cubicular, naturalista, curvilíneo. Esto permite clasificar las tabletas en 25 taxones, identificados con códigos de tres dígitos de acuerdo a la segregación tipológica desarrollada a continuación (Tabla 1).

\section{Antropomorfos}

La figura humana es la que aparece mayormente representada en las tabletas tiwanaku de SPA (13 ejemplares). En panel plano tenemos ocho casos, de los cuales siete se representan en vista frontal y una, en vista lateral. Entre las figuras frontales destacan aquellas de "estilo compacto", correspondiendo a un estereotipo clásico del arte tiwanakota. Se muestra un personaje de complejo atuendo del cual lo más relevante es el tocado cefálico. Este personaje aparece en dos variantes: (a) manos sobre el pecho y (b) brazos desplegados portando cetros. El personaje en vista lateral se ajusta a otro estereotipo tiwanaku, el de un sacrificador que lleva cetro en una mano y hacha con una cabeza cortada en la otra. En las restantes cuatro tabletas con representaciones humanas, los personajes están tallados en volumen y cada uno presenta un estilo distinto.

\subsection{Antropomorfo con brazos extendidos portando cetros}

\subsubsection{En plano-frontal compacto (Figura 2e)} (18272): corresponde a uno de los estereotipos más representativos de Tiwanaku asociado al personaje central de la Puerta del Sol. A diferencia de aquel, éste no luce su cabeza radiada, sino que exhibe un complejo tocado, el que en su segmento superior presenta cabezas de ave y zoomorfa, un pequeño hombre-ave y un elemento de tipo floral ${ }^{2}$. La porción inferior o base está ornamentada con cabezas humanas y felínicas. La túnica es decorada con elementos geométricos y falconiformes, y el faldellín presenta los mismos elementos que la parte inferior del tocado. Ambos cetros exhiben elementos comunes en sus extremos (ave y rostro), pero en el centro hay otros diferentes: el de la mano derecha muestra como componente relevante una especie de caracol con doble cabeza falconiforme y dos de estas mismas cabezas cuelgan por debajo; el de la mano izquierda tiene el mismo elemento floral del tocado. De cada codo cuelga un pompón y de cada 


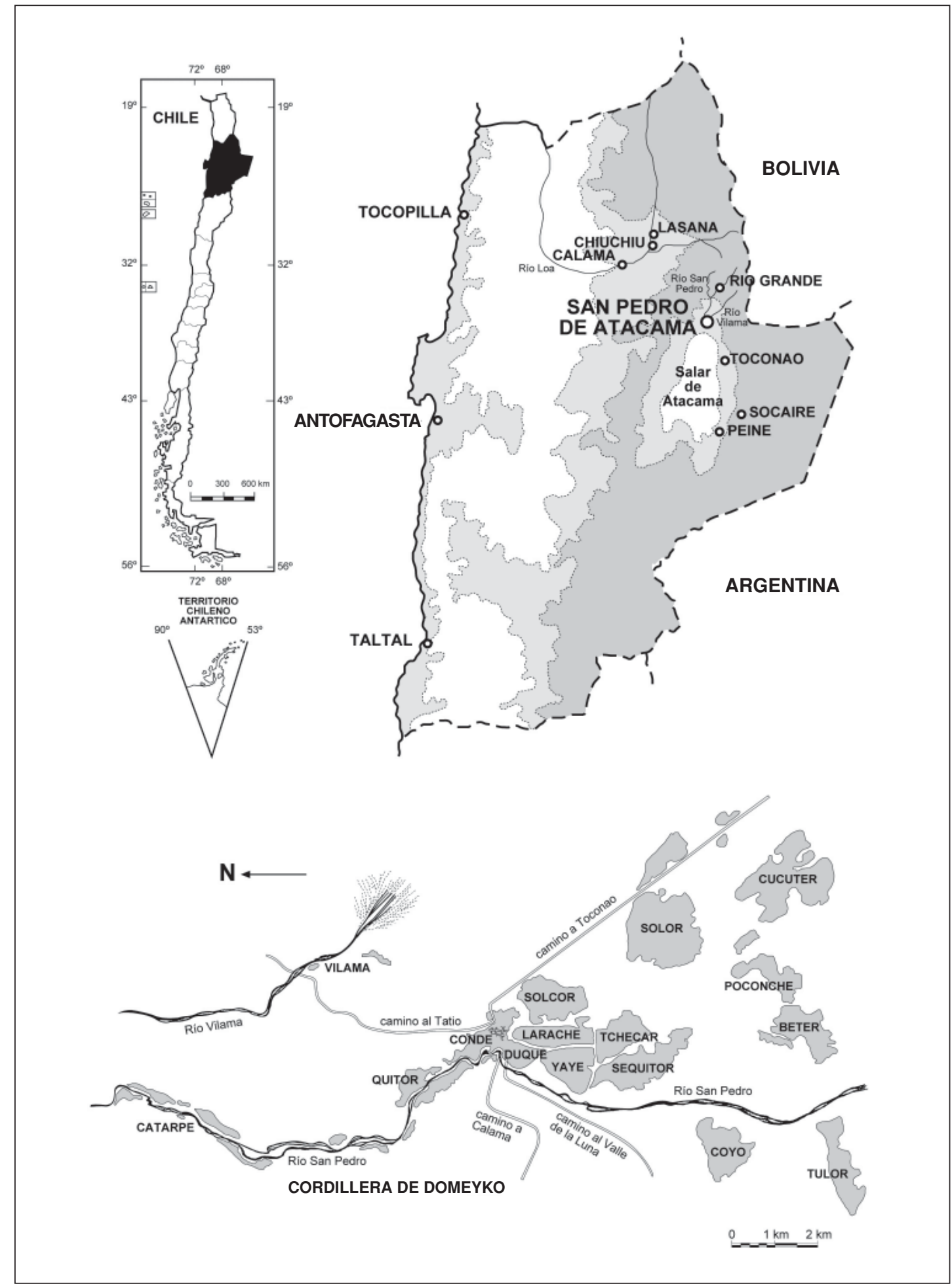

Figura 1. San Pedro de Atacama con la ubicación de los distritos en los cuales hay presencia de tabletas para alucinógenos con iconografía tiwanaku: Quitor, Solcor, Séquitor y Coyo.

San Pedro de Atacama and the locations of the districts containing Tiwanaku iconographic tablets for hallucination: Quitor, Solcor, Séquitor and Coyo. 
pie emerge una prolongación con cabeza de ave. Planos en diversos relieves dan un volumen virtual a la imagen.

\subsubsection{En plano-frontal distendido (Figuras $3 \mathrm{a}, \mathrm{b}$ )} (14666 y 14144): los personajes portando cetros presentan un estilo más naturalístico, menos complejo y sin la compresión ni la distribución segmentaria observada anteriormente; quedan espacios vacíos en el contorno de la silueta. Lo son más simples; uno (Figura 3a) (14666) presenta cuatro apéndices radiales terminados en formas discoidales y las caras no presentan orla en torno a los ojos. Los cetros son sencillos; en un caso simboliza ave y en el otro, pez. Uno de estos personajes se asocia exclusivamente con cabezas de aves (Figura 3a) (14666) y el otro, sólo con peces (Figura 3b) (14144) e incrustaciones de piedra. En ambos se trabajó el cuerpo en sobrerrelieve; los demás elementos se grabaron sobre el panel. A diferencia de la versión compacta, ésta presenta un pedestal escalonado bajo la figura que, por lo menos en un caso (14144), está flanqueado por cabezas de peces. En general, se puede decir que semejan representaciones simplificadas y en un estilo diferente de la figura central de la Puerta del Sol de Tiwanaku.

Tabla 1. Relación de tabletas Tiwanaku, según números de registro del Inventario del

Museo Arqueológico "R.P. Gustavo Le Paige S.J.".

List of Tiwanaku tablets by the inventory number of the registry in the Museo Arqueológico "R.P. Gustavo Le Paige S.J.”.

\begin{tabular}{|c|c|c|c|c|}
\hline № Catálogo & Sitio & Tumba & Taxón & Figura \\
\hline 1045 & Solcor 3 & 4 & 3.1 .1 & $8 \mathrm{a}$ \\
\hline 1075 & Solcor 3 & 5 & 5.0 .1 & $10 \mathrm{a}$ \\
\hline 1112 & Solcor 3 & 3 & 3.1.2. & $8 \mathrm{e}$ \\
\hline 1874 & Solcor 3 & 44 & 5.0 .1 & $10 b$ \\
\hline 2491 & Solcor 3 & 69 & 1.3 .1 & 4 \\
\hline 3722 & Solcor 3 & 99 & 1.2.1. & $2 c$ \\
\hline 8432 & Solcor 3 & 107 & 6.1 .1 & $11 \mathrm{a}$ \\
\hline 8969 & Quitor 6 & 3647 & 3.2.1. & $8 d$ \\
\hline 9047 & Séquitor Alambrado Oriente & 1660 & 1.5 .1 & $6 b$ \\
\hline 9070 & Coyo Oriente (Sur) & 3935 & 2.2.2. & $7 \mathrm{c}$ \\
\hline 9072 & Quitor 6 & $2748-49$ & 3.1 .1 & $8 b$ \\
\hline 9073 & Coyo Oriente (Sur) & 4111 & 7.0 .1 & $13 b$ \\
\hline 9078 & Coyo Oriente (Sur-Sur) & $5351-54$ & 1.2.1. & $2 \mathrm{a}$ \\
\hline 9079 & Séquitor Alambrado Oriente & 1702 & 1.5.2. & $6 c$ \\
\hline 9080 & Quitor 5 & $2183-84$ & 1.1 .3 & $2 \mathrm{f}$ \\
\hline 9081 & Quitor 6 & 3662 & 6.3.1. & $13 \mathrm{a}$ \\
\hline 9082 & Quitor 6 & 2742 & 4.0.1. & $9 \mathrm{a}$ \\
\hline 9083 & Quitor 5 & $2183-84$ & 2.2 .3 & $7 d$ \\
\hline 9084 & Quitor 6 & 3613 & 6.1 .1 & $11 b$ \\
\hline 9085 & Coyo Oriente (Norte) & 4049 & 5.0 .1 & $10 \mathrm{c}$ \\
\hline 9108 & Indeterminado & indeterminada & 3.2.2. & $8 \mathrm{c}$ \\
\hline 9109 & Coyo Oriente (Sur-Sur) & 5299 & 5.0 .1 & $10 \mathrm{~d}$ \\
\hline 9110 & Quitor 6 & 5444 & 6.1 .1 & $11 \mathrm{e}$ \\
\hline 9116 & Coyo Oriente (Sur) & 4141 & 6.2 .1 & $11 d$ \\
\hline 9117 & Coyo Oriente (Sur) & 4008 & 6.2 .1 & $11 \mathrm{c}$ \\
\hline 9119 & Séquitor Alambrado Oriente & 1618 & 2.1.1. & $7 \mathrm{a}$ \\
\hline 9120 & Coyo Oriente (Sur-Sur) & 5381 & 4.0 .1 & $9 b$ \\
\hline 9163 & Quitor 5 & $2189-92$ & 6.2 .2 & 12 \\
\hline 9164 & Quitor 5 & 2196-98 & 1.3.2. & 5 \\
\hline 9166 & Coyo Oriente $(\dot{i})$ & indeterminada & 4.0.2. & $9 \mathrm{c}$ \\
\hline 9315 & Quitor 2 & $3706-07$ & 1.4 .1 & $6 \mathrm{a}$ \\
\hline 14144 & Quitor 6 & 3582 & 1.1.2. & $3 b$ \\
\hline 14665 & Coyo Oriente (Sur) & 3944 & 1.2 .1 & $2 b$ \\
\hline 14666 & Coyo Oriente (Sur) & 4010 & 1.1.2. & $3 a$ \\
\hline 18272 & Coyo Oriente (Sur) & $4093-95$ & 1.1.1. & $2 \mathrm{e}$ \\
\hline 18273 & Quitor 5 & 2235 & 5.0 .1 & $10 \mathrm{e}$ \\
\hline 19110 & Quitor 5 & 1994-96 & 2.2 .1 & $7 \mathrm{~b}$ \\
\hline 20947 & (i) & $(i)$ & 1.2.1. & $2 d$ \\
\hline 20948 & (i) & $3585(i)$ & 4.0.2. & $9 \mathrm{~d}$ \\
\hline
\end{tabular}



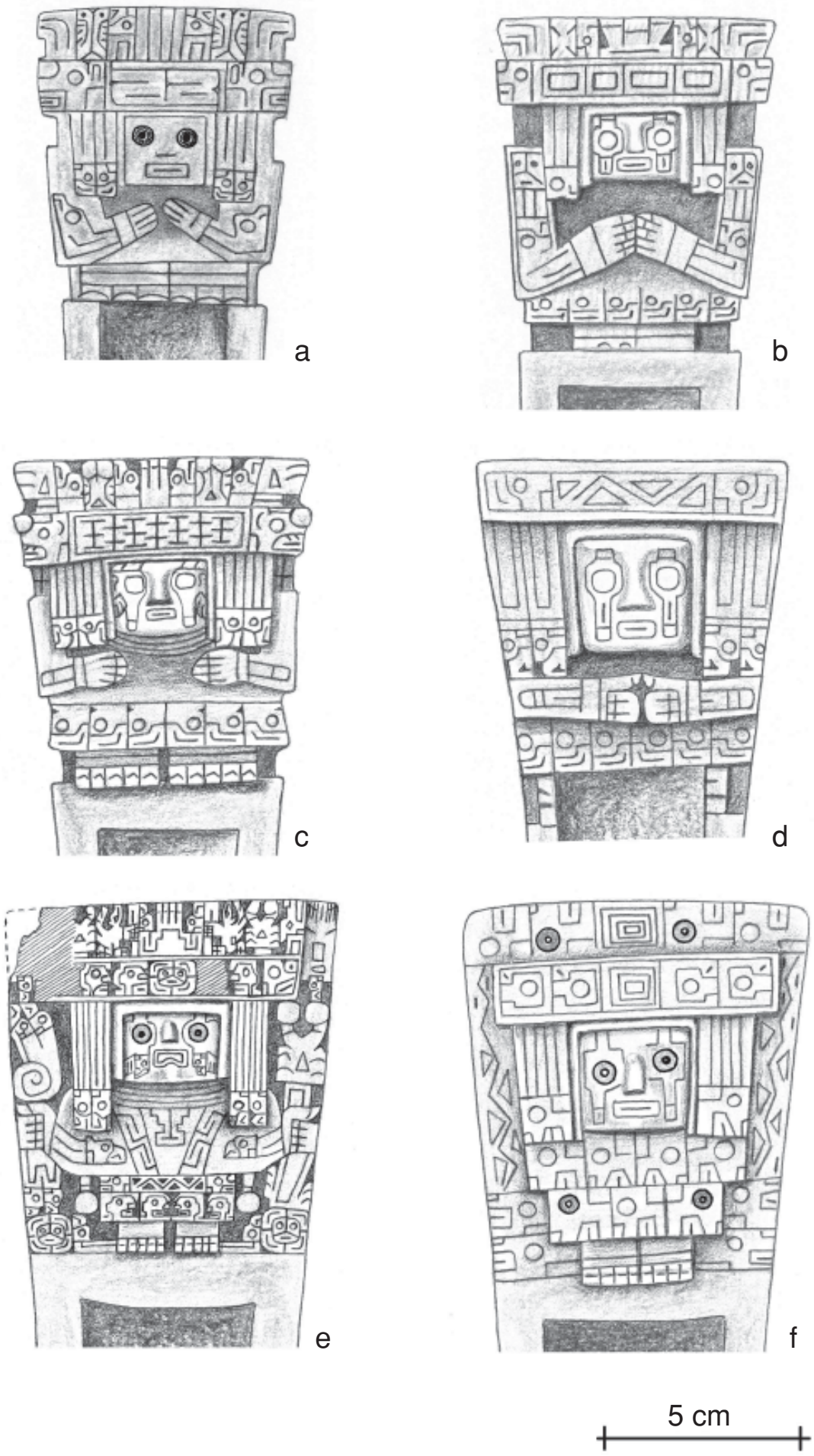

Figura 2. Antropomorfos de patrón plano-frontal: (a) 9078, (b) 14665, (c) 3722, (d) 20947, (e) 18272 y (f) 9080 (dibujos de Agustín Llagostera).

Anthropomorphs of the flat-front style: (a) 9078, (b) 14665, (c) 3722, (d) 20947, (e) 18272 and (f) 9080 (drawings by Agustín Llagostera). 

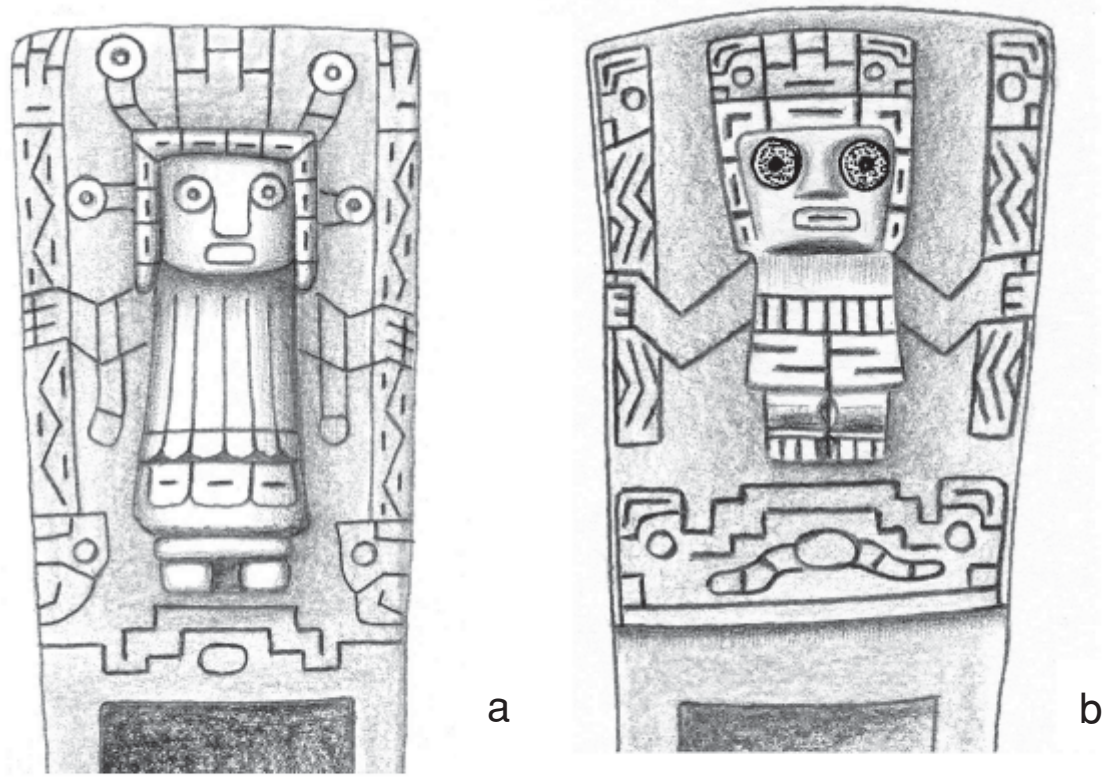

b

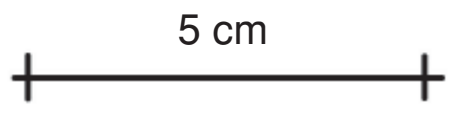

Figura 3. Antropomorfos de patrón plano-frontal distendido: (a) 14666 y (b) 14144 (dibujos de Agustín Llagostera). Anthropomorphs of the flat-front extended style: (a) 14666 and (b) 14144 (drawings by Agustín Llagostera).

1.1.3. En plano-frontal cubicular (Figura 2f) (9080): se presenta como una síntesis del patrón compacto con cetros, pero del cuerpo del personaje sólo están presentes la cara y las extremidades inferiores. Todos los elementos han sido dispuestos en un esquema de rectángulos que cubren totalmente la superficie del panel. En la iconografía secundaria sólo se observan cabezas felínicas. Fue trabajado en juego de relieves dándole relevancia al rostro.

\subsection{Antropomorfo con manos sobre el pecho}

1.2.1. En plano-frontal compacto (Figuras 2a-d) (9078, 14665, 3722 y 20947): es uno de los patrones más clásicos, en el cual el personaje se encuadra compactadamente en cuatro franjas horizontales, correspondiendo la superior al tocado, la segunda a la cabeza y tronco y la tercera a las extremidades inferiores. A veces existe otra franja inserta entre la segunda y la tercera que delimita el faldellín o borde de la túnica. El tocado se compone de dos partes y difiere levemente de la del personaje compacto de los cetros: la parte superior combina cabezas de falcónidas con elementos complementarios, especialmente de tipo plumario y fitomorfo; la inferior presenta elementos geométricos en la parte central y una cabeza de felino a cada lado. Cabeza y tronco de la entidad forman un bloque compacto. A los costados de la cabeza cuelga la cabellera en forma de cintas dobles o simples que terminan en cabezas de falcónidas o peces. Los brazos flexionados apoyan las manos sobre el pecho. El faldellín o borde de la túnica generalmente está compuesto por una secuencia de cabezas de peces. En las comprimidas extremidades inferiores se han delineado tres a cinco dedos. La técnica de grabado ha sido complementada con juego de altos y bajos relieves, con especial realce del rostro. El ejemplar 20947 es más simple que los anteriores, ya que su tocado es de un solo estrato; no presenta extremidades inferiores; porta ca- 
bezas de peces en el tocado y faldellín, y de aves en la cabellera; a diferencia de los anteriores, sus manos están invertidas en relación a lo que sería una posición normal y no tiene extremidades inferiores (Figura 2d). Todas ellas carecen de pedestal escalonado.

\subsection{Antropomorfo portando hacha y/o cabeza cercenada}

1.3.1. En plano-lateral (Figura 4) (2491): se ajusta al patrón clásico tiwanaku de representaciones en vista lateral con personajes genuflexos. El ejemplar analizado lleva una imagen con todos sus rasgos antropomorfos y con una prominente nariz. El tocado presenta elementos ictio y ornitomorfos, además del tipo floral. Mano frontal (derecha) con cetro; mano posterior (izquierda) con hacha y cabeza. El soporte del tocado y el cetro tienen el mismo motivo que la proyección bucal; el tocado además porta una cabeza de pez en su extremo frontal. Pedestal de tres escaños y cabezas ictiomorfas a cada lado. En la iconografía secundaria hay sólo peces.

\subsubsection{En volumen naturalista (Figura 5) (9164):} representado por un Sacrificador con atributos humanos y sin ornamentación compleja; posee una cabeza casi tan grande como el cuerpo. En la mano izquierda porta la cabeza cortada y en la derecha, el hacha. Lleva una especie de casco liso con largo penacho que cae por la espalda. En el extremo distal de la caja se proyecta un segmento del panel, el que presenta un sacado en la parte central, a modo de almena, en el cual está posado el personaje. El pedestal es de un escaño, con proyecciones laterales angulares terminadas en cabezas felínicas, cada una porta tocado simple. Los ojos del Sacrificador son incrustaciones de turquesa.

\subsection{Antropomorfo en asociación con aves y camélidos}

1.4.1. En volumen compacto (Figura 6a) (9315): es la única representación compuesta en la que al personaje principal se le han agregado figuras de camélidos y falcónidas, no como iconografía secundaria sino como parte de una idea de relación asociativa. Pareciera ser una versión del estereotipo compacto pero en patrón volumétrico; presenta el mismo esquema y los mismos aditamentos de aquellos. A su vez, se asemeja a las esculturas monolíticas de Tiwanaku. Se trata de la reproducción de estos monolíticos personajes, la que en este caso porta un ave de rapiña en cada hombro y camélidos bajo cada uno de los muñones que representan sus brazos. Tanto el borde de la cabellera como el del faldellín están ornamentados con cabezas de peces. La conformación soportante es similar a la de la Figura 5 (9164). El pedestal se compone de tres escaños con cabezas felínicas a cada lado, coronadas cada una de ellas por dos cabezas de peces. Cada tocado ictiomorfo sirve a su vez de pedestal a los camélidos.

\subsection{Antropomorfo sin aditamentos}

1.5.1. En volumen recostado (Figura 6b) (9047): una representación tridimensional muestra a una figura humana en posición decúbito ventral, recostada sobre el panel de la tableta. El panel, en la parte próxima a la caja, lleva grabadas una cabeza de felino a cada lado e incrustaciones de piedras rojas y azules. Es probable que, además, en este mismo espacio, haya tenido dos pequeñas

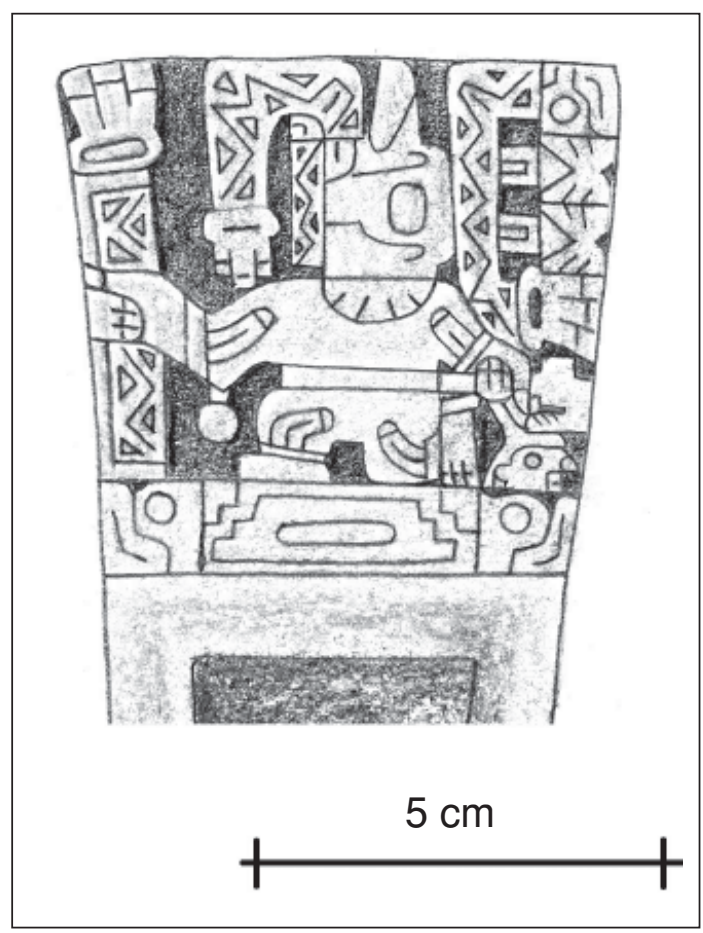

Figura 4. Antropomorfo de patrón plano-lateral (Sacrificador): 2491 (dibujo de Agustín Llagostera).

Anthropomorph of the flat-lateral style (Sacrificer): 2491 (drawing by Agustín Llagostera). 


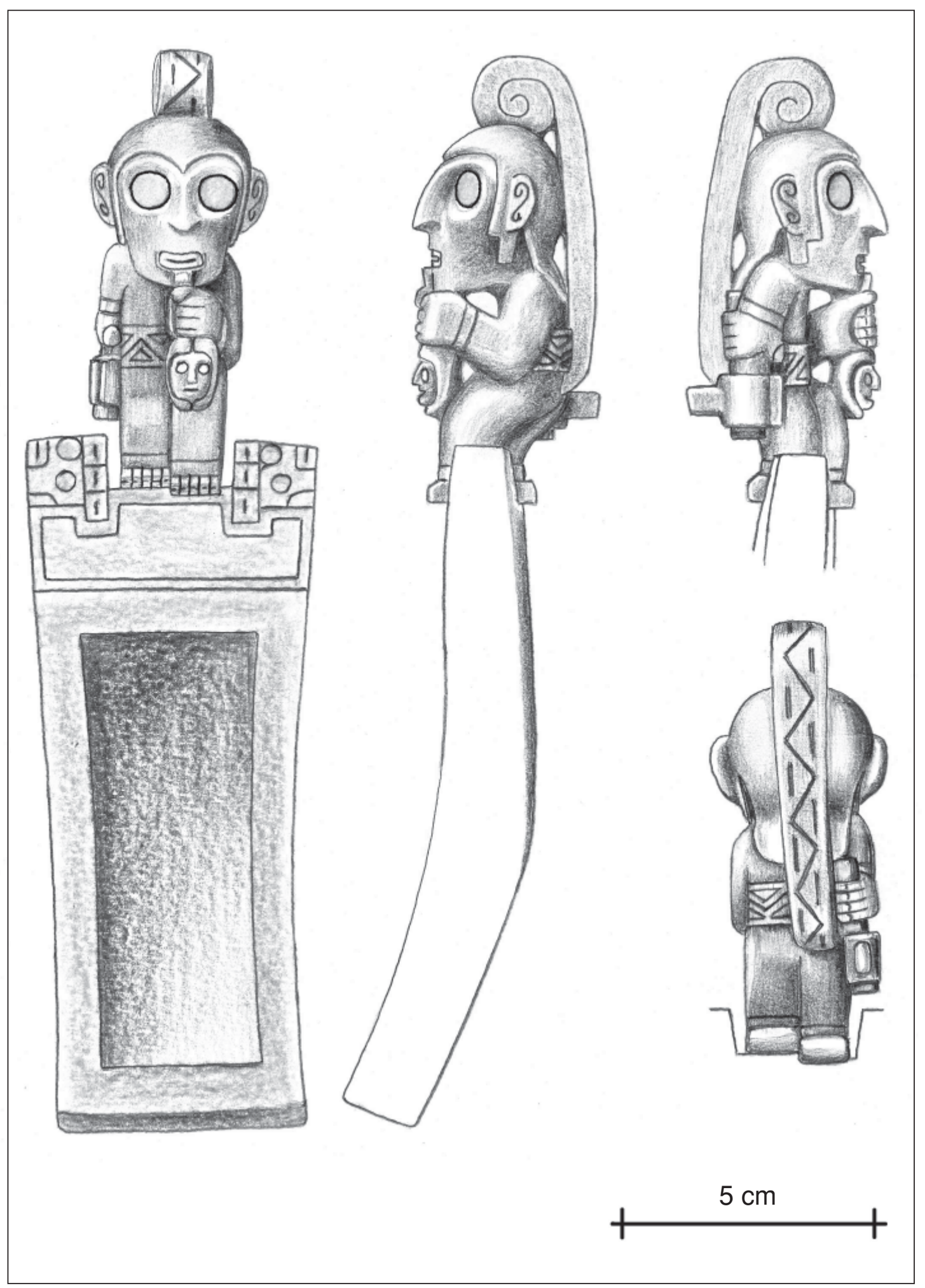

Figura 5. Antropomorfo de patrón volumétrico naturalista: 9164 (dibujos de Agustín Llagostera). Anthropomorph of the volumetric naturalistic style: 9164 (drawings by Agustín Llagostera). 

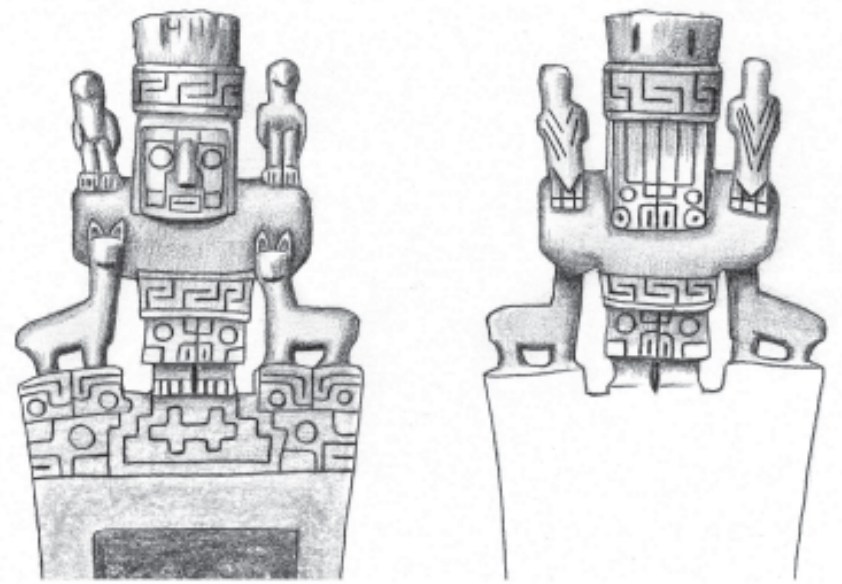

a

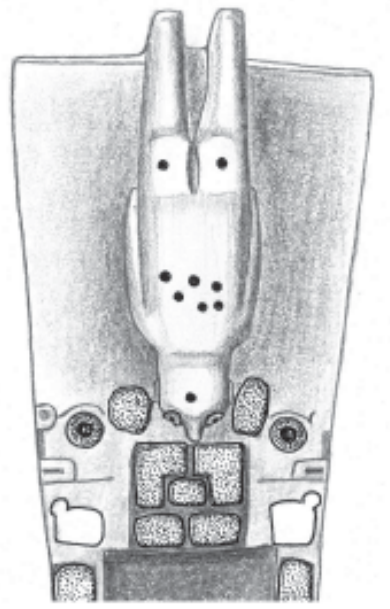

b
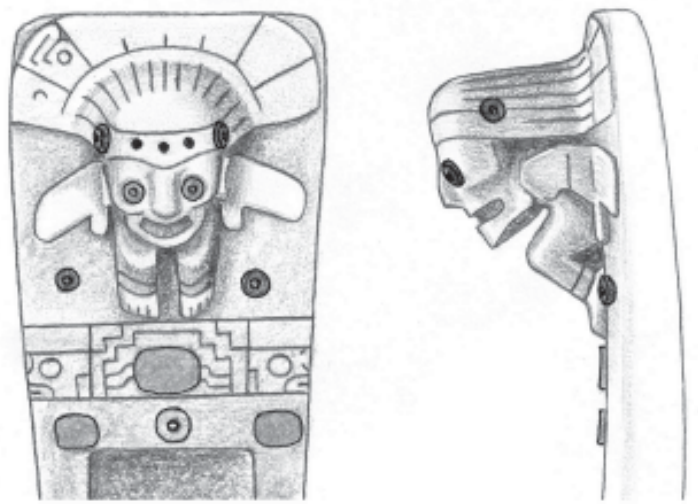

C

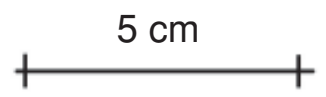

Figura 6. Antropomorfos de patrón volumétrico naturalista: (a) 9315, (b) 9047 y (c) 9079 (dibujos de Agustín Llagostera). Anthropomorphs of the volumetric naturalistic: (a) 9315, (b) 9047 and (c) 9079 (drawings by Agustín Llagostera). 
incrustaciones de hueso en forma de cabezas felínicas (similares a Figura 13a) (9081). Pequeños clavos de oro aparecen incrustados en el cuerpo del personaje y también en el borde proximal de la tableta. Es posible que la posición del cuerpo se relacione con los sacrificios humanos, siendo probablemente ésta la postura en que se ponía a las víctimas para ser decapitadas.

1.5.2. En volumen sentado (Figura 6c) (9079): es una figura humana que aparece sentada sobre el panel plano, apoyándose en las manos, con la cabeza semiinclinada hacia atrás y una larga cabellera que cae y se abre en forma de abanico sobre el panel. Cabeza y manos son desproporcionadamente grandes. El borde de la cabellera ha sido grabado sobre el panel, configurado por una secuencia de cabezas de peces. El pedestal de tres escaños, en este caso, está grabado en el panel, a los pies de la figura y aparece flanqueado por dos cabezas felínicas con tocado simple. Tiene incrustaciones en ojos, oídos, panel y, también, en el borde superior de la caja.

\section{Cefalomorfos}

Existen cuatro tabletas con representación de cabezas humanas sin cuerpos y todas ellas aparecen en vista frontal planimétrica.

\subsection{Cefalomorfo con cetros}

2.1.1. En plano-frontal (Figura 7a) (9119): Cabeza rectangular con orla de discos o pompones. De la parte superior se proyectan dos cabezas de pez y de cada costado, cuatro cintas terminadas en discos; del mentón, otra cinta con disco, muy larga, y de cada lado de la parte inferior de la cabeza se desprende una cinta que se flexiona hacia el borde del panel (a modo de brazos), terminada en cabeza de pez (lo que parece representar las manos). Desde aquí se yerguen cetros terminados en cabezas humanas. La figura cefalomorfa no muestra contacto con el pedestal, por lo que parece flotar sobre él. El pedestal es de tres escaños asociado con cabezas felínicas coronadas.

\subsection{Cefalomorfo sin aditamentos}

2.2.1. En plano-frontal curvilíneo (Figura 7b) (19110): cabeza discoidal rodeada por una greca anular que exhibe trazos angulares contrapuestos, desde donde irradian proyecciones terminadas en discos o en cabezas de falcónidas. Dos cabezas de peces unen el mentón y el pedestal. Este último tiene tres escaños con proyecciones laterales flectadas, terminadas en cabezas de felinos.

\subsubsection{En plano-frontal cubicular (Figura 7c)} (9070): representación compacta, ajustada a un panel ajedrezado y cuyos componentes adoptan una simetría sagital. Cabeza subrectangular rodeada por una greca segmentada de la cual emergen proyecciones menores terminadas en discos y otras, más gruesas, conformadas por cabezas de felino. Coincidiendo con cada esquina distal del panel, hay una gran cabeza de felino. Entre la cabeza principal y el pedestal se extiende una franja con cuatro cabezas de felinos. El pedestal de dos escaños está incluido en otra franja que se completa con las cabezas felínicas laterales, las que llevan tocado simple.

2.2.3. En plano-frontal simple (Figura 7d) (9083): en el panel plano se muestra, como única representación grabada, una cabeza rectangular muy simple. Ni la cara ni el resto del panel presentan ornamentación secundaria, sólo una incrustación de piedra entre la cabeza y la caja.

\section{Felinomorfos}

La representación del felino se hace presente cinco veces; tres veces con sólo una imagen y dos veces en imagen doble simétrica. Sobre panel plano han sido grabadas dos imágenes simples y una doble y, en técnica mixta (combinación planimétrica y volumétrica), tenemos un ejemplar doble y otro simple. Como patrón constante, las representaciones planimétricas siempre muestran al felino de perfil. Las únicas representaciones dobles de personajes que se registran en la colección de tabletas tiwanaku se asocian con felino.

\subsection{Felinomorfo simple}

3.1.1. En plano-lateral (Figuras 8a, b) (1045 y 9072): dos ejemplares de tabletas que muestran al felino grabado en panel plano y en vista lateral. Ambos ejemplares son muy diferentes entre sí. Uno (Figura 8a ) (1045), representa al felino en forma muy realista, levitando sobre una franja que en su interior contiene un pedestal de dos escaños 

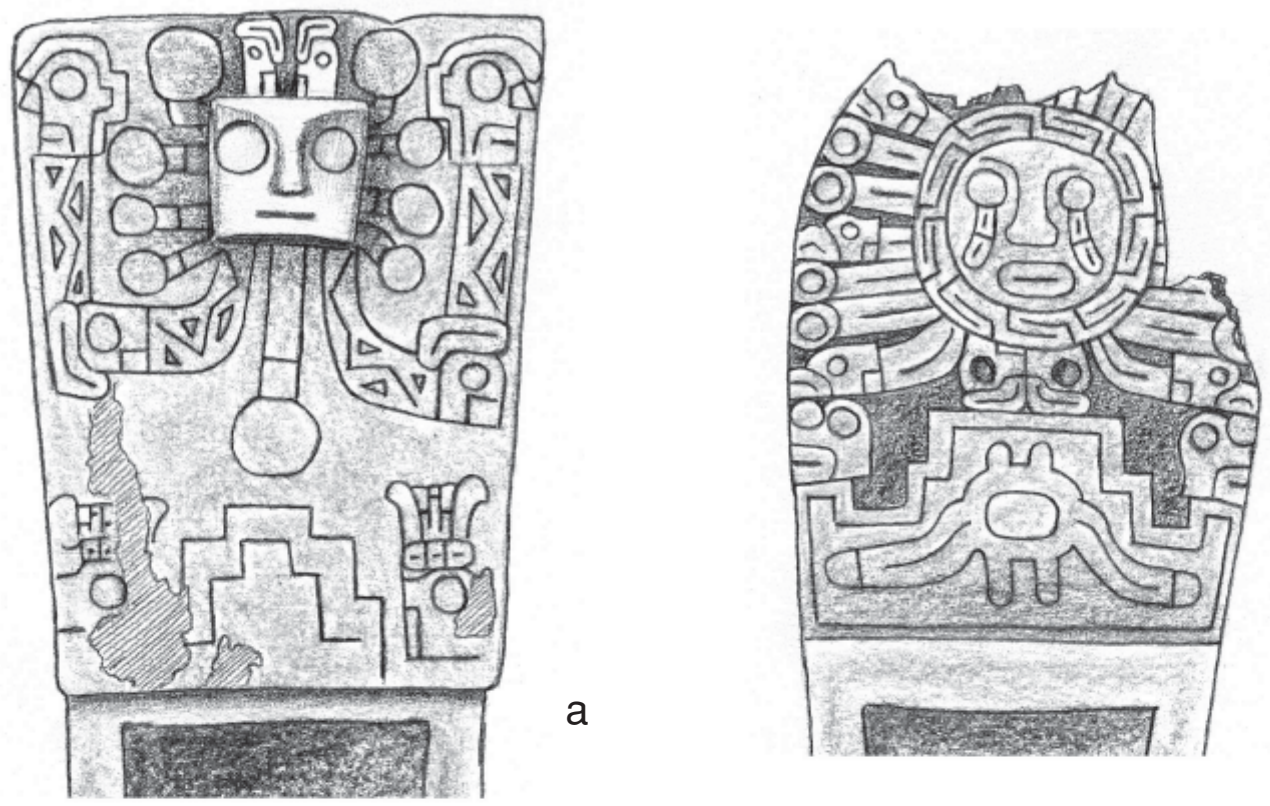

b
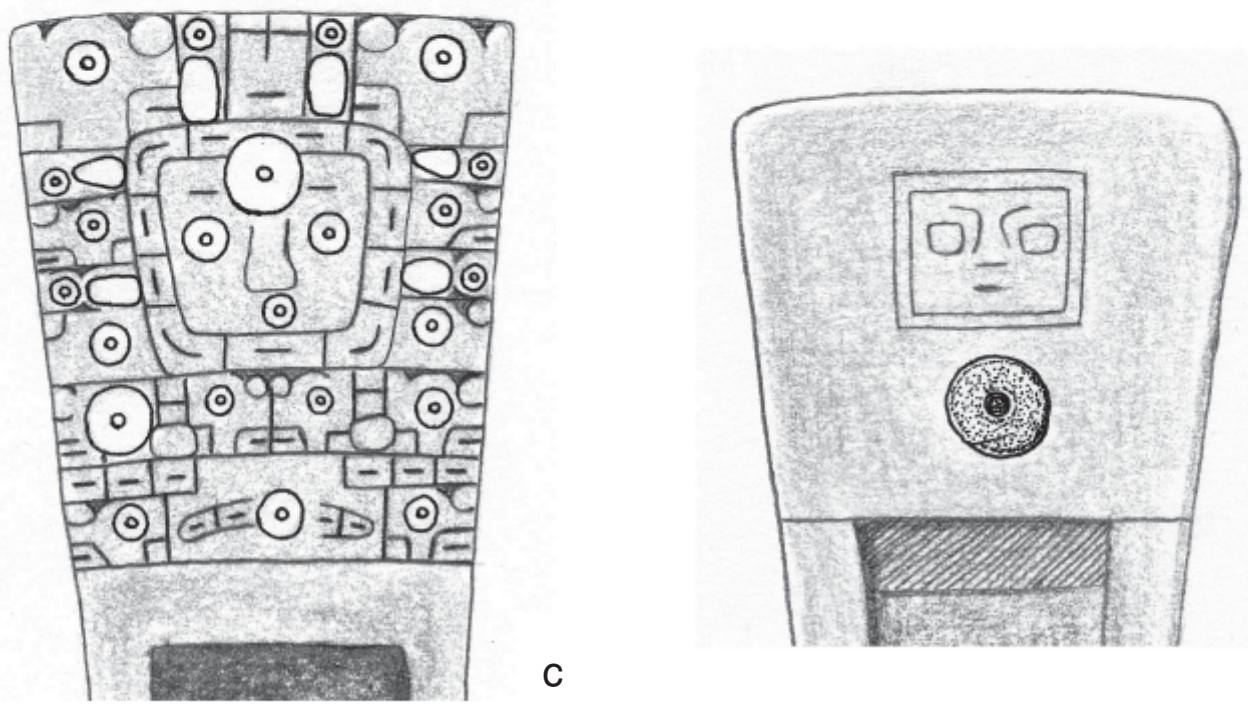

C

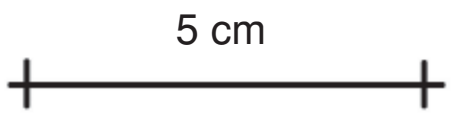

Figura 7. Cefalomorfos: (a) 9119, (b) 19110, (c) 9070 y (d) 9083 (dibujos de Agustín Llagostera). Cephalomorphs: (a) 9119, (b) 19110, (c) 9070 and (d) 9083 (drawings by Agustín Llagostera). 

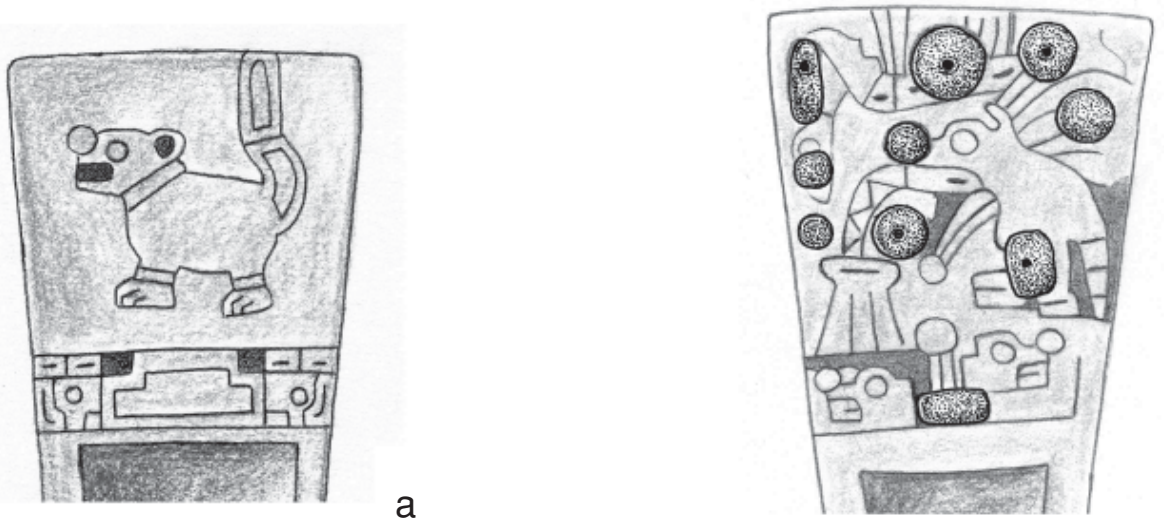

b
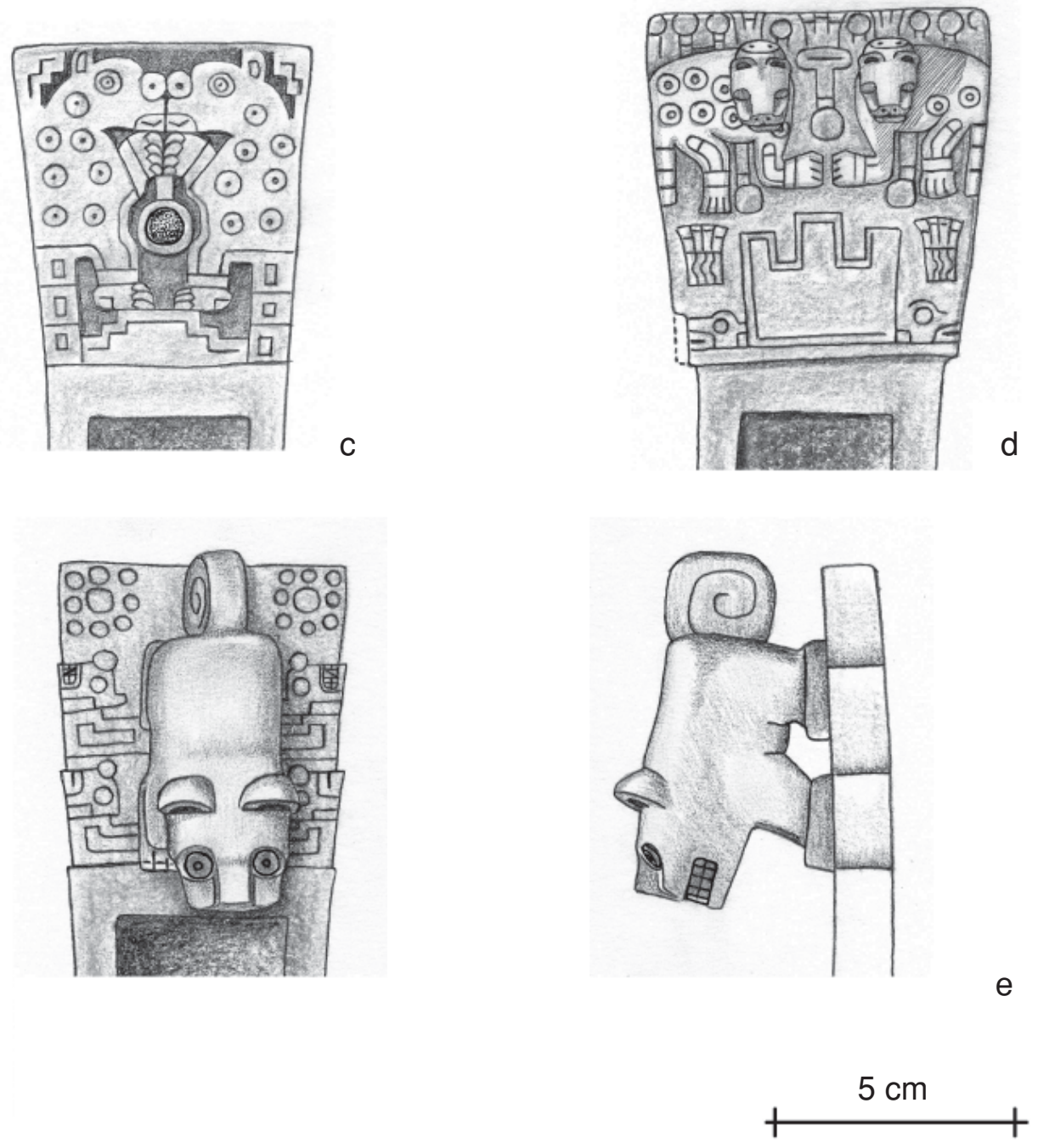

Figura 8. Felinomorfos: (a) 1045, (b) 9072, (c) 9108, (d) 8969 y (e) 1112 (dibujos de Agustín Llagostera).

Felinomorphs: (a) 1045, (b) 9072, (c) 9108, (d) 8969 and (e) 1112 (drawings by Agustín Llagostera). 
y cabezas laterales ictiomorfas, con tocado simple. El otro ejemplar (Figura 8b) (9072) muestra al animal semierguido sobre sus extremidades posteriores, rodeado de elementos estilísticamente atípicos. Sobre él flota lo que podría ser un tocado, con una cabeza falconiforme colgando de su parte anterior; no presenta pedestal escalerado, pero sí, cabezas falcónidas laterales. Exhibe una proyección bucal típica. Se le han agregado numerosas incrustaciones de piedra.

\subsubsection{En volumen naturalista (Figura 8e) (1112):} se trata del cuerpo completo de un felino esculpido en tres dimensiones, posado sobre sus cuatro patas, perpendicularmente sobre el panel de la tableta. La imagen es bastante realista. En el panel se ha grabado, en cada esquina distal, un círculo rodeado de ocho círculos menores, y emergiendo de cada pata hay una proyección terminada en cabeza de felino. Las cabezas de las patas posteriores muestran dentadura expuesta, en tanto que las anteriores tienen la boca cerrada. Los ojos y dentadura de la figura principal han sido ejecutados con incrustaciones de piedra.

\subsection{Felinomorfo doble}

3.2.1. En modo mixto (Figura 8d) (8969): en el caso de la tableta asignada a este tipo, son las cabezas de una representación dupla de felinos, las que sobresalen tridimensional y frontalmente del panel. Los cuerpos, extremidades y cola se han diseñado en vista lateral en el panel y en simetría enfrentada, en un moderado relieve. El resto de los elementos solamente ha sido grabado sobre el panel. Se trata de felinos moteados que no llevan tocado, pero sí elementos que la representan sobre el lomo. El pedestal no es escalonado, sino de doble tronera y flanqueado por cabezas felínicas. En la nuca de cada felino está grabado un pequeño rostro circular.

3.2.2. En plano-lateral (Figura 8c) (9108): el único ejemplar representa dos felinos erguidos sobre sus extremidades posteriores, enfrentándose mutuamente en un eje de simetría. Ambos son ejemplares moteados posados sobre un pedestal de tres escaños, el que carece de cabezas laterales. Los espacios que contornean a los animales han sido rebajados para resaltar las figuras.

\section{Falconimorfos}

Entre las falcónidas, la única especie que aparece como entidad principal en las tabletas tiwanaku es el cóndor. En dos tabletas aparece representado planimétricamente y en otras dos, en patrón volumétrico. En tres de las señaladas el ave aparece en actitud hierática y en otra, se le representa escenográficamente engullendo a un hombre-ave.

4.0.1. En plano-lateral (Figuras 9a, b) (9082 y 9120): se hace presente en dos ejemplares bajo esquemas muy diferentes. Uno, trata de un cóndor posado con las alas extendidas, realizado bajo el canon típico tiwanakota (Figura 9a) (9082). El tocado es bastante simplificado. Lo que serían las cubiertas alares se proyectan por debajo de las alas propiamente tales y están representadas por dos cabezas ictiomorfas. Una proyección con elemento tripartito (plumiforme) emerge de la pata anterior. Plataforma de dos escaños y cabezas ictiomorfas laterales aparecen compactadas en una greca por debajo de la composición principal. El otro ejemplar representa la escena de un cóndor devorando un hombre-ave (Figura 9b) (9120). El cóndor bastante realista, sin tocado, está posado sobre un ente que tiene cabeza humana y cuerpo de ave; una prolongación que sale de la cabeza de esta criatura se introduce en el pico del ave, significando el acto de engullir. En una sección inferior, claramente delimitada, se desarrolla el motivo del pedestal piramidal con proyecciones laterales angulares terminadas en cabezas de felino.

\subsubsection{En volumen naturalista (Figuras 9c-d) (9166} y 20948): representaciones naturalistas del cóndor, talladas en tres dimensiones, ocupando el lugar del panel; el ave tiene las alas semiabiertas, su cabeza mira de frente y exhibe un rostro tripartito sobre el pecho. Elementos del canon tiwanacota se observan en crestas laterales, ojos y alas. En el extremo distal de la caja se proyecta un segmento del panel, el que presenta un sacado en la parte central, a modo de almena, en el cual está posada el ave. Este recorte delimita y enmarca las cabezas de felino coronadas que se ubican al extremo de proyecciones angulares a los costados del pedestal. Se diseñaron cabezas de aves en la orla ocular y en las alas; de pez en los cubrealas y de felinos en el pedestal. El otro ejemplar es bastante más simple y menos ornamentado (Figura 9d) (20948). La 

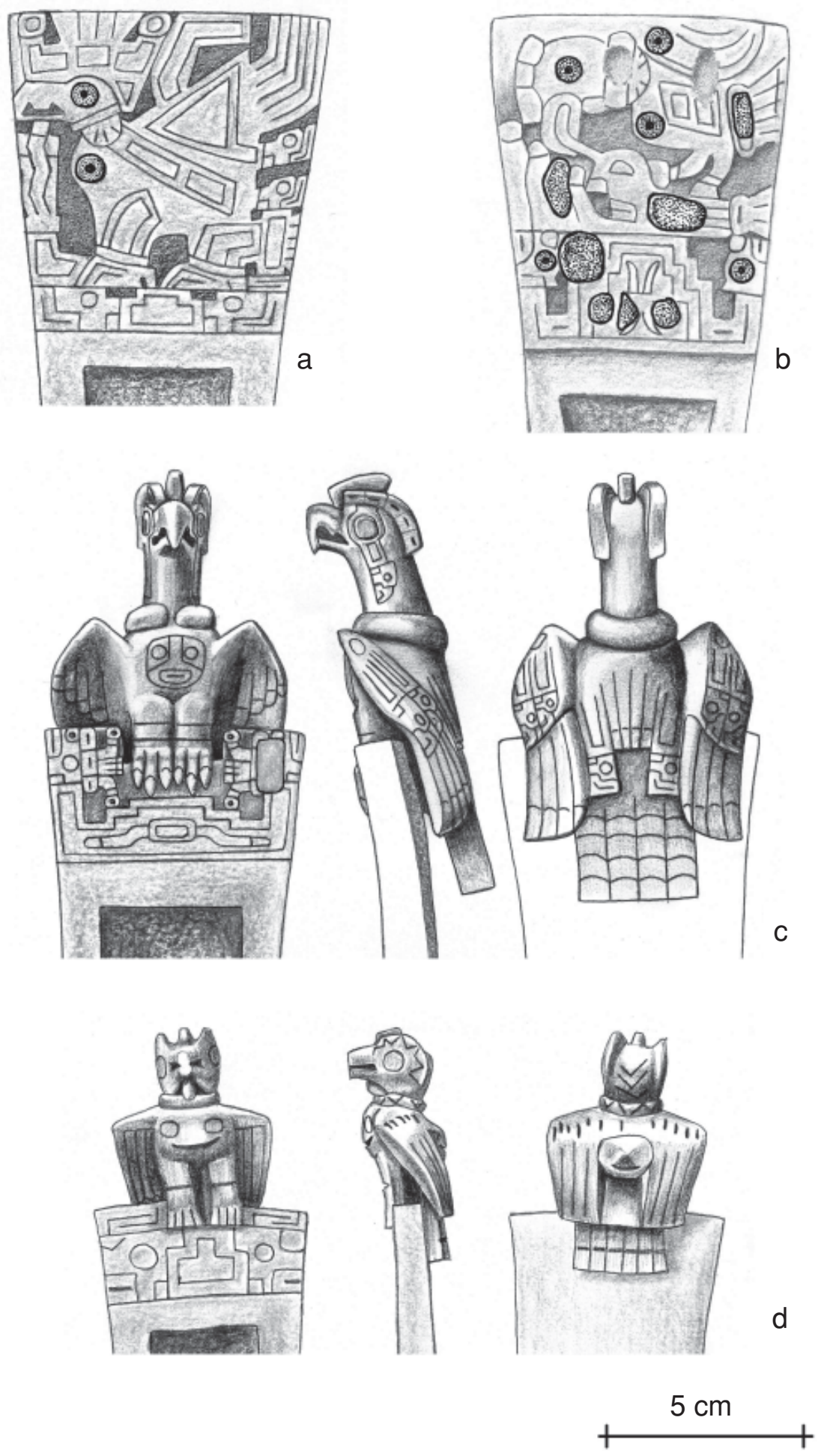

Figura 9. Falconimorfos: (a) 9082, (b) 9120, (c) 9166 y (d) 20948 (dibujos de Agustín Llagostera). Falconimorphs: (a) 9082, (b) 9120, (c) 9166 and (d) 20948 (drawings by Agustín Llagostera). 
base, a diferencia del anterior, es levemente almenada y hace parte de una franja compacta que involucra pedestal de dos escaños y cabezas laterales de felino. Además del rostro que lleva en el pecho, hay otro que se insinúa en el dorso.

\section{Camelidomorfos}

En las tabletas tiwanaku conocidas hasta ahora todos los camélidos presentan el mismo estereotipo de representación: la imagen del animal ha sido grabada en panel plano, de perfil, mirando hacia el lado izquierdo del observador, y cargando una entidad cefalomorfa sobre el lomo. No es posible determinar a cuál de las cuatro especies de camélidos se ha querido representar (guanaco, vicuña, llama o alpaca); la protuberancia que a veces se observa sobre su frente podría representar el mechón que caracteriza a la alpaca (Figuras 10a, c).

5.0.1. En plano-lateral (Figuras 10a-e) $(1075,1874$, 9085, 9109 y 18273): son cinco ejemplares que se adscriben al mismo y único subtipo. En algunos casos se ha aplicado rebaje en los espacios que contornean la figura. Lleva tocado en su cabeza, un pendiente con medallón al cuello que se origina en las orejas y, recorriendo el lomo, una especie de capa que remata en una cabeza de felino en vista frontal. Este camélido siempre carga a su espalda un bulto constituido por una cara humana ataviada con tocado simple o complejo. Lleva una especie de faldellín, que también podría representar la caída lateral del manto de lana, ornamentado con cabezas falconiformes. Generalmente expone una dentadura con algunos dientes curvados, al igual que los camélidos machos. Pueden tener proyecciones en las patas terminadas en pequeñas cabezas: de ave la delantera y fitomorfa la trasera. En general, las pequeñas cabezas que rematan las proyecciones pueden ser: sólo de aves o sólo de felinos en la misma tableta, tanto en la imagen principal como en el pedestal, o de aves en la figura principal y de felinos en el pedestal. El ejemplar 9085 (Figura 10c) destaca por su complejidad y finura en el grabado, siendo ésta una de las eximias obras del arte tiwanaku. El ejemplar 18273 (Figura 10e) podría ser considerado como una variedad asignable al patrón cubicular, ya que la representación se ha compactado y simplificado al máximo con un predominio de líneas rectas, enca- sillando los motivos en un sistema de cubículos. La tableta 9109 (Figura 10d) fue recortada en algún momento del pasado, cercenando la imagen a la altura de la calota del animal y de la cabeza que éste lleva sobre la grupa. Los pedestales de tres escaños, en cuatro casos, presentan cabezas felínicas laterales (tres con tocado) y en un caso, con cabezas falconiformes. Es interesante constatar que en la iconografía secundaria de estos camélidos se encuentran excluidas las pequeñas cabezas de peces.

\section{Teratomorfos}

Se trata de entes monstruosos resultantes de la hibridación de dos especies diferentes. En esta categoría se incluyen seis tabletas; cinco de ellas representan entes que tienen el cuerpo de humano y la cabeza o la dentadura de felino. En cuatro de ellas estas criaturas han sido grabadas en panel plano, de perfil, en posición genuflexa y mirando hacia arriba; en una quinta, se le representa tallada volumétricamente. Otro ente teratomorfo, del cual se conoce solo un ejemplar, parece ser una serpiente cascabel o un yacaré con orejas.

\subsection{Antropo-felinomorfo}

6.1.1. En plano-lateral (Figuras 11a, b, e) (8432, 9084 y 9110): se trata de personajes grabados en tabletas planiformes y bajo uno de los más clásicos estilos tiwanakota; es decir, genuflexo mirando hacia arriba, con tocado, cetro y proyección oral. En este grupo se segregan aquellos entes que siendo totalmente antropomorfos lucen una dentadura felínica, portan hacha y cabeza o sólo hacha en su mano izquierda; exhiben una greca con motivos geométricos bajo el mentón y son poseedores de una prominente nariz. Hay que hacer notar que hay sólo un caso que carece de pedestal (Figura 11e) (9110). La más sofisticada de estas tabletas es la 8432 (Figura 11a), la única que presenta calado en los contornos de la figura.

\subsection{Antropo-felino-ornitomorfo}

6.2.1. En plano-lateral (Figuras 11c, d) (9117 y 9116): en este caso el patrón representativo es muy similar al anterior, pero toda la cabeza del ente es de felino; también porta cetro en su mano derecha pero no está representado el brazo izquierdo 

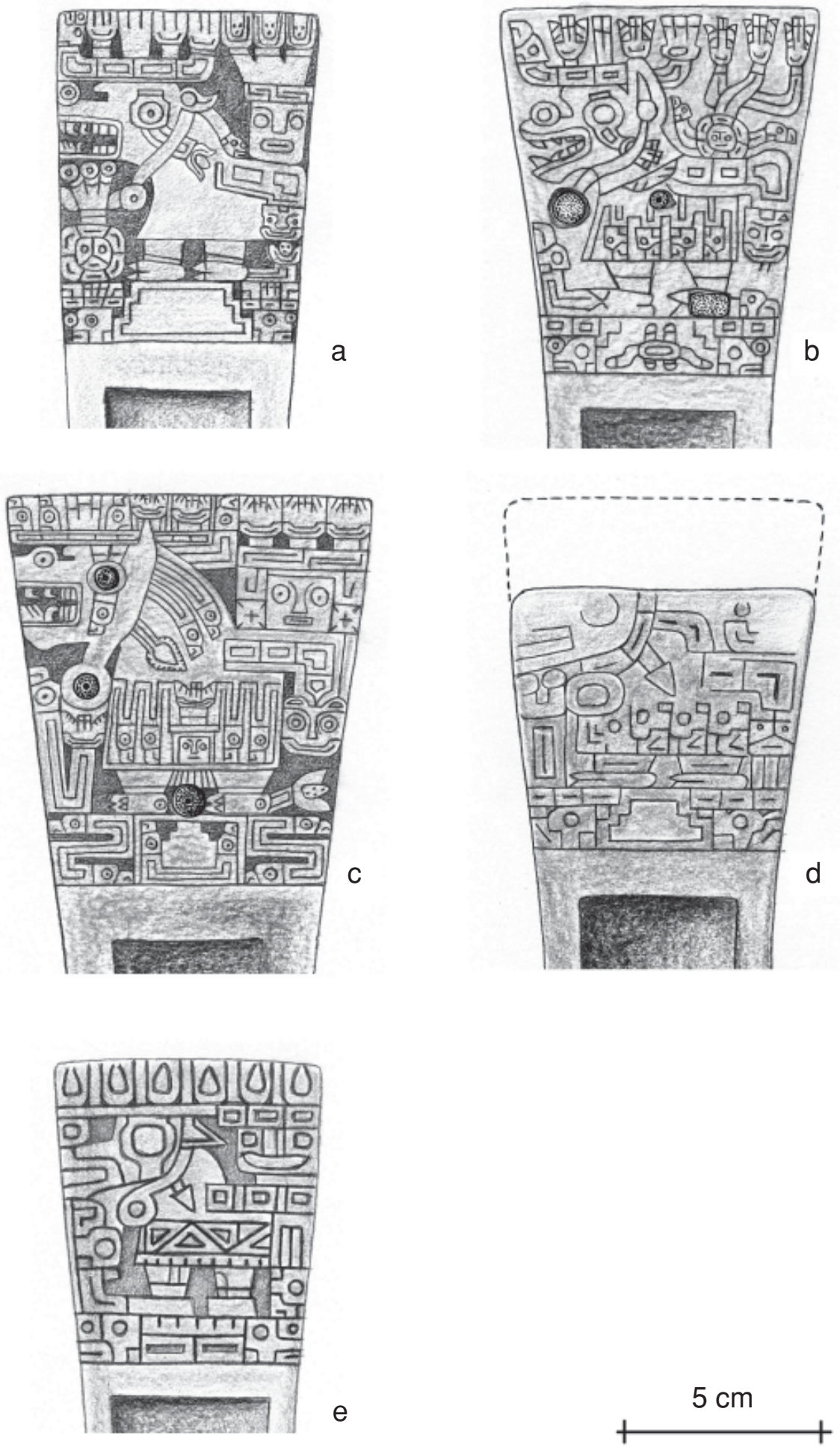

Figura 10. Camelidomorfos: (a) 1075, (b) 1874, (c) 9085, (d) 9109 y (e) 18273 (dibujos de Agustín Llagostera). Camelidomorphs: (a) 1075, (b) 1874, (c) 9085, (d) 9109 and (e) 18273 (drawings by Agustín Llagostera). 

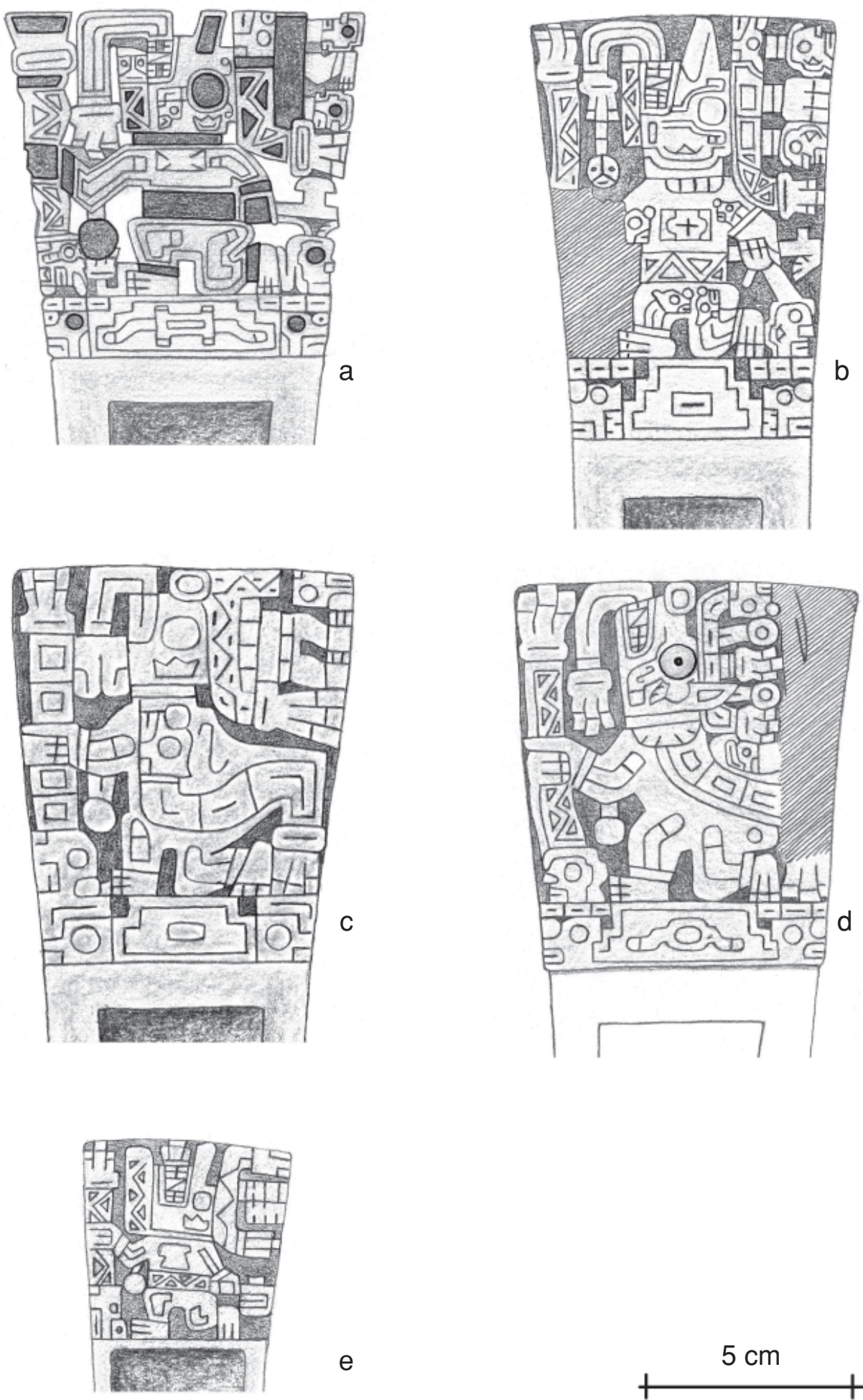

e

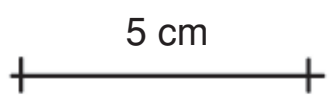

Figura 11. Teratomorfos: (a) 8432, (b) 9084, (c) 9117, (d) 9116 y (e) 9110 (dibujos de Agustín Llagostera). Teratomorphs: (a) 8432, (b) 9084, (c) 9117, (d) 9116 and (e) 9110 (drawings by Agustín Llagostera). 
y lleva una especie de capa que termina en un elemento plumario; en el ejemplar 9116 (Figura 11d), a pesar de lo erosionado del sector, se infiere presencia de alas a su espalda. La iconografía secundaria está expresada por cabezas antropomorfas y felínicas; sólo en un caso aparecen cabezas ictiomorfas flanqueando el pedestal (Figura 11c) (9117).

\subsubsection{En volumen (Figura 12) (9163): existe una} notable representación de un sacrificador en actitud de imitar el desplazamiento de un felino. Tiene cuerpo humano y cabeza de felino o una máscara que representa a dicho animal. Sobre el dorso se observa lo que se podría definir como la síntesis de un felino alado. Porta hacha y cabeza cercenada y, delante de la imagen, existe un bloque rectangular que podría representar el altar de sacrificio. Catorce cabezas de felino y sólo una de falcónida complementan la iconografía secundaria; la única cabeza de falcónida se ubica en el altar; en la nuca del ente protagonista se ha grabado un rostro tripartito.

\subsection{Reptilomorfo}

6.3.1. En modo mixto (Figura 13a) (9081): sobre el panel, en relieve y en planta con vista dorsal, se observa lo que pareciera ser la representación de una serpiente cascabel o un yacaré con una gran cabeza en la que se distingue un par de orejas, resultando un híbrido entre reptil y mamífero. A ambos costados del panel se distribuyen los grabados de un elemento plumiforme, de dos cabezas felínicas (una de ellas corresponde a una incrustación de hueso grabado) y, además, de una cabeza falconiforme también de hueso. Hacia el borde distal, dos incrustaciones circulares.

\section{Indeterminados}

7.0.1. En plano (Figura 13b) (9073): existe un caso que escapa a las categorías precedentes y que no es posible asimilar a ningún ente identificable. Se trata de un grabado en panel plano de dos cintas que se abren en "V" y que terminan cada una en una cabeza felínica, con otra cabeza igual en un apéndice que emerge a la mitad de cada cinta. Entre las dos cintas, una tercera que termina en una especie de penacho. Esta tableta tiene una gran cantidad de pequeños clavos de oro y numerosas incrustaciones de piedras.

\section{Contextualización Ergológica}

Contextualmente, los portadores de tabletas para alucinógenos de impronta tiwanaku no difieren sustancialmente de otros miembros de los repositorios funerarios correspondientes. En cuanto al número de individuos por tumba se da la siguiente relación: 27 tumbas con un individuo, tres tumbas con dos, tres tumbas con tres y dos con cuatro. Evidentemente, hay un alto predominio de tumbas individuales, pero esto es prácticamente una de las características del período en que se insertan estas inhumaciones. Hay que destacar que todos son de sexo masculino y están acompañados de arcos y flechas; tubos, espátulas y cucharillas asociadas a las prácticas alucinogénicas; y de un equipo para confeccionar cuentas de collar compuesto de un cincel con punta de bronce y tablilla-soporte con escarificaciones provocadas por la manufactura de las cuentas sobre ellas. Entre otros objetos, aunque menos frecuentes y que pueden estar señalando determinadas especializaciones, tenemos dos casos con martillos de piedra de tipo minero, ambos proceden de Coyo Oriente, y dos con instrumentos musicales: una trompeta de madera y una flauta de hueso. Dentro de la diversidad de componentes del ajuar no asociado a género, se encuentran: alfarería, cestería, capachos, collares y adornos en piedras cupríferas, cucharas y partes de camélidos como ofrendas (especialmente cabezas).

Un aspecto más específico, es la asociación con tubos de características Tiwanaku, que se manifiesta en promedio de $38 \%$ de tabletas asociadas con tubos inhalatorios de la misma filiación; el resto está representado por tubos simples sin ninguna decoración.

En cuanto al componente alfarero, se encuentran tumbas con una a 10 piezas cerámicas, concentrándose las mayores frecuencias entre una, dos y tres piezas, lo cual puede ser considerado como característica del período, así como también la presencia de tumbas sin cerámica. De las 34 tumbas consideradas, $22(54,5 \%)$ contienen piezas de alfarería y $12(45,5 \%)$ carecen de ellas. Cabe destacar que la tumba con mayor número de alfarería (10) pertenece al período Temprano de SPA, siendo esto una característica propia de ese período.

La presencia de mazos y de hachas la hemos definido como símbolos de poder (Llagostera 1996). En este sentido, cabe destacar que el $47 \%$ (16) de los portadores de tabletas tiwanaku portan 


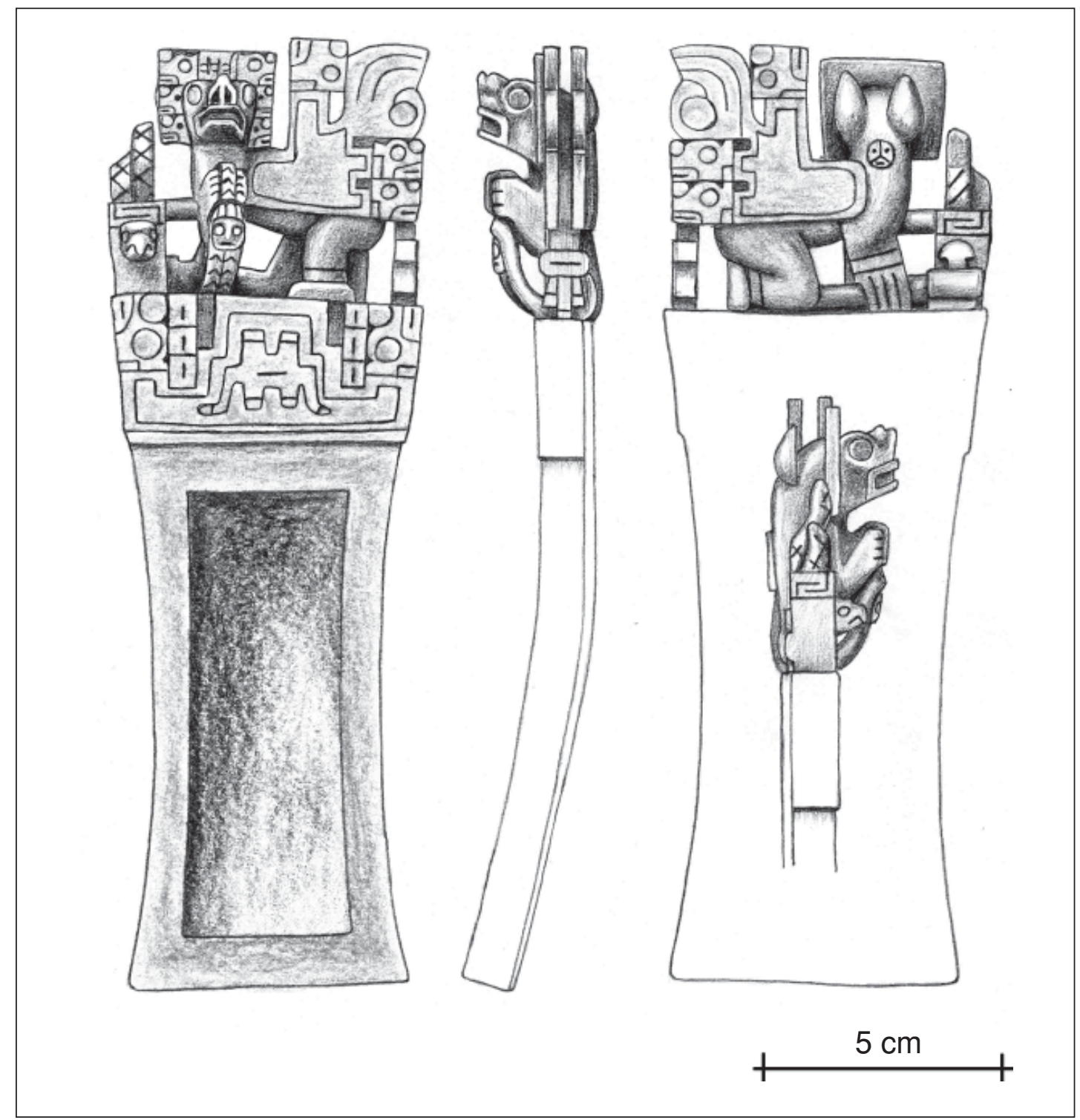

Figura 12. Teratomorfo volumétrico: 9163 (dibujos de Agustín Llagostera).

Teratomorph volumetric: 9163 (drawings by Agustín Llagostera).

también hachas, al que si le sumamos la presencia de dos mazos, nos sube a 56\%. Esto es el indicador más relevante para evaluar el estatus de los portadores de tabletas tiwanaku. Varias hachas están representadas solamente por el mango, al que se le ha quitado la hoja metálica y se la ha reemplazado por una hoja simbólica de hueso, de madera o de piedra tosca. Este reemplazo indica, por un lado, que las hojas de metal eran difíciles de obtener, por lo cual sólo en excepcionales ocasiones eran enterradas con el difunto. El $82 \%$ de las hachas asociadas a portadores de tabletas tiwanaku entra en la categoría de simbólicas. Parece ser que lo más común era que al morir el titular, la hoja de metal fuera "heredada" por otro personaje, el que asumiría el estatus pertinente. Esto potencia, con mayor fuerza, el valor simbólico y a la vez jerárquico de las hachas dentro de los códigos de poder al interior del grupo y en cuanto a las redes de interacción externas para la obtención de las hojas metálicas. 


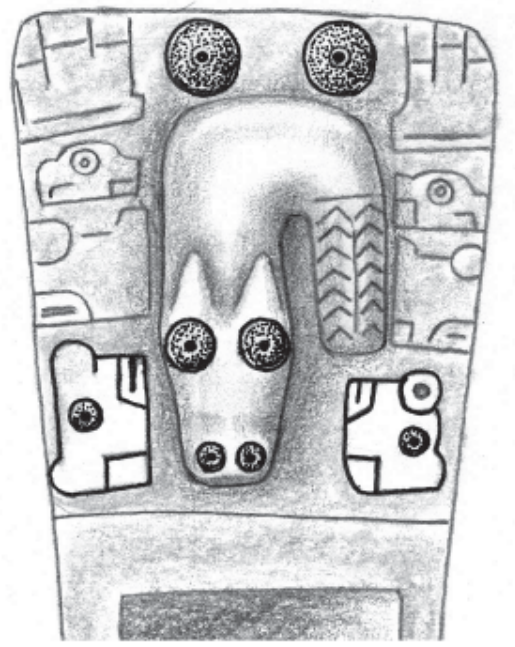

a

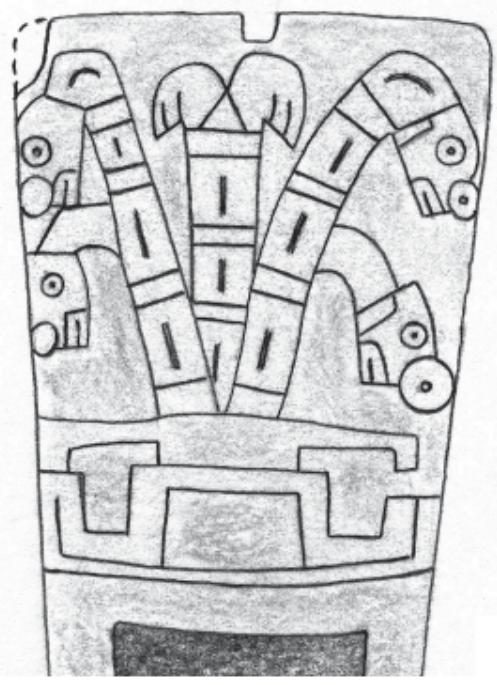

b

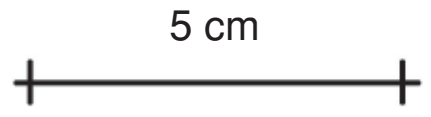

Figura 13. Teratomorfo volumétrico parcial: (a) 9081; Indeterminado planimétrico: (b) 9073 (dibujos de Agustín Llagostera). Teratomorph partial volumetric: (a) 9081; Indeterminate planometric: (b) 9073 (drawings by Agustín Llagostera).

La asociación con metales también la hemos considerado como evidencia de estatus. Se da el caso de cuatro portadores de tabletas tiwanaku asociados con objetos de metal: 10 adornos de plata en forma de discos con un orificio central, una cinta de cobre, numerosos adornos de cobre en forma de campanitas de cuatro puntas, un caso en que el mismo portador de campanitas de cobre tiene un tubo inhalador revestido con láminas de oro. Es importante acotar que estas cuatro asociaciones con metales se relacionan a su vez con hachas.

Además de las tabletas tiwanaku y de los tubos de la misma filiación, otros componentes foráneos dan testimonio de una compleja y dinámica red de interacción puneña; destacan: un cesto "tipa" de los que se han definido como procedentes del noroeste argentino (Llagostera 1995) y una alfarería de forma troncocónica invertida. Esta cerámica es de color rojo con diseños en negro y asa cinta vertical que lleva adherida la figura de un cuadrúpedo; no tenemos referente para asignar procedencia a esta pieza, sin embargo, podemos asegurar que no es de filiación Tiwanaku, al menos no Tiwanaku clásico. Además, aparecen conchas de caracol de procedencia transandina (Strophocheilus).

\section{Contextualización Espacial}

De los 25 tipos iconográficos (taxones) segregados, 17 de ellos son únicos (con un ejemplar cada uno) y ocho se repiten. Entre estos últimos, tenemos cinco con dos, uno con tres, uno con cuatro y uno con cinco. Los taxones más frecuentes son el antropomorfo con manos sobre el pecho en planofrontal compacto y camelidomorfos en plano-lateral, con cuatro y cinco ejemplares respectivamente (Tabla 2).

Coyo Oriente es el sitio que registra la mayor cantidad de tabletas tiwanaku (12); le siguen Quitor 6, Solcor 3 y Quitor 5 (7, 7 y 6, respectivamente); por último Séquitor Alambrado Oriente y Quitor 2 (3 y 1). Quitor 2, Quitor 5 y Séquitor Alambrado Oriente no repiten taxones; Quitor 6 y Solcor 3 repiten un taxón y Coyo Oriente repite tres taxones.

Quitor 2 registra una única y exclusiva tableta de un tipo que no es compartido con ningún otro sitio. Séquitor Alambrado Oriente tiene tres tabletas, de las cuales dos son antropomorfas volumétricas, aunque distintas, y una cefalomorfa radiada. La iconografía secundaria en el primer sitio está 
Tabla 2. Distribución de las tabletas por taxones en cada uno de los sitios. Distribution of the tablets by taxons in each site.

\begin{tabular}{|c|c|c|c|c|c|c|c|c|}
\hline Taxón & Coyo Or. & Quitor 2 & Quitor 5 & Quitor 6 & Sq.Al.Or. & Solcor 3 & Sin registro & Subtotales \\
\hline 1.1.1. & 1 & & & & & & & 1 \\
\hline 1.1 .2 & 1 & & & 1 & & & & 2 \\
\hline 1.1.3. & & & 1 & & & & & 1 \\
\hline 1.2.1. & 2 & & & & & 1 & 1 & 4 \\
\hline 1.3 .1 & & & & & & 1 & & 1 \\
\hline 1.3 .2 & & & 1 & & & & & 1 \\
\hline 1.4.1. & & 1 & & & & & & 1 \\
\hline 1.5 .1 & & & & & 1 & & & 1 \\
\hline 1.5 .2 & & & & & 1 & & & 1 \\
\hline 2.1 .1 & & & & & 1 & & & 1 \\
\hline 2.2.1. & & & 1 & & & & & 1 \\
\hline 2.2.2. & 1 & & & & & & & 1 \\
\hline 2.2.3. & & & 1 & & & & & 1 \\
\hline 3.1 .1 . & & & & 1 & & 1 & & 2 \\
\hline 3.1.2. & & & & & & 1 & & 1 \\
\hline 3.2 .1 & & & & 1 & & & & 1 \\
\hline 3.2 .2 . & & & & & & & 1 & 1 \\
\hline 4.0.1. & 1 & & & 1 & & & & 2 \\
\hline 4.0 .2 . & $1 ?$ & & & & & & 1 & 2 \\
\hline 5.0.1. & 2 & & 1 & & & 2 & & 5 \\
\hline 6.1.1. & & & & 2 & & 1 & & 3 \\
\hline 6.2.1. & 2 & & & & & & & 2 \\
\hline 6.2 .2 & & & 1 & & & & & 1 \\
\hline 6.3.1. & & & & 1 & & & & 1 \\
\hline 7.0.1. & 1 & & & & & & & 1 \\
\hline Totales & 12 & 1 & 6 & 7 & 3 & 7 & 3 & 39 \\
\hline
\end{tabular}

representada por cabezas de felino y en el segundo por cabezas de felinos, peces y humanos.

Quitor 5 presenta seis tabletas, cada una de un tipo diferente. Este sitio comparte uno de sus tipos con Solcor 3. Las dos entidades cefalomorfas presentes en el sitio difieren entre sí, por ser una muy elaborada (Figura 7b) (19110) y la otra muy simple (Figura 7d) (9083). Uno de los sacrificadores es antropomorfo (Figura 5) (9164) y el otro es teratomorfo (Figura 12) (9163); ambos pueden ser catalogados dentro de las más eximias obras volumétricas del arte tiwanakota. Hay que hacer notar que las tabletas 9083 (Figura 7d) y 9080 (Figura 2f), aún perteneciendo a un mismo individuo de una misma tumba (T-2183-84), son de estilos muy disímiles. La iconografía secundaria está presente sólo con cabezas felínicas y de falcónidas.

Quitor 6 registra siete tabletas, todas diferentes, excepto dos que comparten un taxón. Cuatro tipos son compartidos con otros sitios: dos con Coyo Oriente y dos con Solcor 3. Dos de los tres ejemplares del personaje de nariz prominente, con dentadura felínica, proceden de Quitor 6; el otro pertenece a Solcor 3; este último (Figura 11a) (8432) difiere notablemente por su técnica en relación a los de Quitor 6. El antropomorfo con cetros se aproximaría al de Coyo Oriente (Figura 3a) (14666) en cuanto al patrón distendido, pero en un estilo diferente. Sólo hay dos representaciones de felinos duplos en la colección total; uno pertenece a este sitio (Figura 8d) (8969) y el otro es de procedencia desconocida (Figura 8c) (9108), pero ambos son diferentes entre sí. La generalidad de estas tabletas presenta en su iconografía secundaria cabezas de felino, humanas y también de aves, habiendo dos que sólo presentan cabezas ictiomorfas (Figuras 9a y 3d) (9082 y 14144).

Solcor 3 aporta con siete tabletas de iconografía tiwanaku, todas de diferente tipo, a excepción de dos que se asimilan a un mismo taxón. Tres tipos son compartidos con otros sitios: dos con Quitor 6 y uno con Coyo Oriente y Quitor 5. En el 
sitio se repite dos veces el camélido de perfil pero en dos estilos muy diferentes. Hay dos personajes genuflexos de nariz prominente; uno de ellos con dentadura felínica expuesta (Figura 11a) (8432) y el otro, no (Figura 4) (2491). El primero, es la única tableta conocida del Período Medio de SPA a la que se ha aplicado la técnica de calado. Cabezas de felinos, aves, peces y humanas constituyen el stock en la iconografía secundaria.

Coyo Oriente es poseedor de 12 tabletas, habiendo seis taxones con sólo un ejemplar y tres con dos ejemplares. Cuatro de los tipos son compartidos con otros sitios: uno con Solcor 3, dos con Quitor 6, uno con Quitor 5 y Solcor 3. A pesar de la cantidad de taxones en este sitio (9), las entidades se reducen a siete: antropomorfos con manos en el pecho, antropomorfos con cetros, cefalomorfos, camelidomorfos, falconimorfos, teratomorfos $\mathrm{y}$ uno no definido. El personaje con cetros aparece en una versión extremadamente compleja (Figura 2e) (18272) y otra muy simple (Figura 3a) (14666). Una de las dos versiones del camélido de perfil es también una extremada sofisticación de la entidad. El personaje de los cetros y este camélido parecen haber sido manufacturados por el mismo artista, dada la magistral ejecución del grabado. El cóndor volumétrico (Figura 9c) (9166), por su excelente calidad, es comparable con los sacrificadores de Quitor 5 (Figuras 12 y 5) (9163 y 9164). La entidad teratomorfa se muestra en tres versiones, una con cabeza de felino, dentadura expuesta, y alada, otra, con cabeza felínica pero boca cerrada y sin alas, y una tercera, con cabeza zoomorfa y cuerpo de ave. La única versión cefalomorfa es de tipo compacto cubicular (Figura 7c) (9070).

\section{Contextualización Temporal}

En relación a la contextualización temporal de las tabletas tiwanaku halladas en SPA, no podemos dejar de referirnos a lo señalado por Torres (2001), en el sentido de que la fecha más temprana asociada a un ajuar inhalatorio con iconografía tiwanaku en esta localidad es una datación por termoluminiscencia de 190 d.C. (no calibrado), obtenida de una tumba de Toconao Oriente. A esto se agregan otras dos tabletas que se encontrarían en asociación con cerámica del tipo Rojo Pulido, lo que las ubicaría entre 300 a.C. y 100 d.C. La situación de estas tabletas tempranas la hemos discutido anteriormente (Llagostera 1996). Estas table- tas, si bien es cierto traen ya el canon tiwanakota del personaje genuflexo lateralizado y del personaje frontal, carecen de los atributos secundarios, como las pequeñas cabezas de felinos, falcónidas y peces, así como del pedestal, que caracteriza la iconografía clásica de Tiwanaku; por lo cual, consideramos que ellas estarían relacionadas con las etapas o fases iniciales del desarrollo de la entidad Tiwanaku en el altiplano.

A excepción de las anteriores, prácticamente todas las tabletas tiwanaku de la colección atacameña serían asignables a la Fase Coyo (700-950 d.C.), especialmente por su asociación con cerámica Negra Casi Pulida (Le Paige 1964, 1965) o Gris Gruesa Pulida (Tarragó 1968, 1989). Sólo tres tabletas se asociarían a un momento previo de transición, entre las fases Quitor y Coyo (anterior a 700 d.C.), asociadas con cerámica Negra Pulida (Figuras 9a, d y 10e) (9082, 18273 y 20948). Entre estas últimas se cuenta el ejemplar 9082 (Figura 9a) que pertenece a Quitor 6, tumba 2742, siendo portador de cerámica Negra Pulida, incluyendo un botellón antropomorfo, típicos indicadores de la Fase Quitor (Tarragó 1989); el ejemplar 18273 (Figura 10e) pertenece a Quitor 5, tumba 2235; aunque éste sólo tiene cerámica común, no diagnóstica, espacialmente se ubica en un sector de tumbas con alfarería Negra Pulida (Norte Centro); el ejemplar 20948 (Figura 9d) procede de Quitor 5, tumba 1994-96, y se asocia con cerámica Negra Pulida, incluyendo también un botellón antropomorfo.

Se puede intentar una secuencia espacial con base en tres cementerios, basándose en la sectorización descrita por Le Paige; ellos son Quitor 5, Quitor 6 y Coyo Oriente. Los dos primeros presentan una similar distribución de tabletas, es decir, los ejemplares tiwanakotas se hallan en tumbas de la fase Coyo, pero se concentran predominantemente en la zona de transición; es decir, donde se interdigitan las tumbas de las fases Quitor y Coyo. En tanto, una minoría de ellas fue encontrada en el sector ocupado sólo por tumbas de la Fase Coyo. Por su parte, el cementerio de Coyo Oriente es un repositorio asociado exclusivamente a la Fase Coyo, o que, de acuerdo a los apuntes de Le Paige, se puede dividir en tres sectores: norte, sur y sursur. Los contextos y las fechas disponibles para este último sitio hablarían en favor de una secuencia que avanza en el tiempo de sur a norte, distribuyéndose las tabletas en la siguiente forma: tres en el sector sur-sur, ocho en el sector sur y una en el 
sector norte. Es interesante acotar que, al igual que en Quitor 5 y Quitor 6, en los momentos tardíos de la Fase Coyo las tabletas tiwanaku son muy escasas.

De la batería de fechas asociada a tabletas (Tabla 3) resultaría que el rango cronológico en el que se concentran las tabletas tiwanaku en SPA iría aproximadamente desde 500 hasta 1.000 d.C. ${ }^{3}$ Complementando el dato cronológico con la seriación espacial, las tabletas tiwanakotas más tempranas en SPA, aparte de aquellas asociadas a alfarería Roja Pulida, son las 9082 y 18273 (Figuras 9a, 10 e) y se alojan en Quitor 6 y Quitor 5. En tanto, la más tardía sería la 9085 (Figura 10c) de Coyo Oriente (norte). Entre estos dos extremos se ubicaría la totalidad de las 37 tabletas restantes. El análisis precedente nos hace ver que estamos enfrentados a dos momentos en el período Medio (Fase Coyo); uno inicial ubicado estimativamente entre 500 y 900 d.C. (Llagostera et al. 1988) al cual se adscribiría el mayor flujo de tabletas Tiwanaku, y uno final, entre 900 y 1.200 d.C., donde se observa una declinación de estos artefactos. Sin embargo, el análisis iconográfico comparativo entre las tabletas que se agrupan en cada uno de los momentos no hace posible distinguir atributos propios para cada momento, ni establecer una seriación iconográfica entre las tabletas.

\section{Discusión y Conclusiones}

Aunque la cultura Tiwanaku manifiesta cierta estandarización en sus cánones estilísticos, hay un alto porcentaje de tabletas que no responde a los estereotipos más difundidos, sino a patrones hasta ahora desconocidos en la iconografía tiwanakota. Esto habla de una gran diversidad de estilos y procedencias. Para las 39 tabletas analizadas en este artículo hemos definido 25 taxones, cumpliendo con la expresión de atributos que permiten catalogarlas como tiwanakotas, quedando en evidencia que una alta proporción de estos artefactos presenta características disímiles que las hacen prácticamente únicas.

La representación antropomorfa es la categoría predominante con 13 ejemplares; a su vez, dentro de ella prevalece el patrón plano-frontal, al que sigue el patrón volumétrico; se contabiliza sólo un caso para el patrón plano-lateral. Entre las figuras plano-frontales existe igual cantidad de antropomorfas con brazos extendidos y portando cetros, que las antropomorfas con manos sobre el pecho. Siempre en el rubro antropomorfo, el personaje sacrificador aparece en una única versión planolateral y en un ejemplar volumétrico. Las representaciones cefalomorfas, felinomorfas, falconimorfas, camelidomorfas y teratomorfas se hacen presentes en un rango de cuatro a seis ejemplares, en tanto que las reptilomorfas e indefinidas presentan un solo caso cada una.

El patrón plano-lateral es el más común y está presente en 16 tabletas, siendo sus estereotipos los personajes genuflexos y los camelidomorfos. Sigue el patrón plano-frontal representado por 13 tabletas, resaltando los estereotipos antropomorfos de brazos extendidos portando cetros, antropomorfos con manos sobre el pecho, y cefalomorfos, entidades representadas exclusivamente en

Tabla 3. Fechaciones asociadas a tumbas portadoras de tabletas Tiwanaku (fechas no calibradas). Associated dates from tombs with Tiwanaku tablets (dates not calibrated).

\begin{tabular}{lccl}
\hline Sitio & Tableta & Fecha & Referencia \\
\hline Solcor 3 & 13166 & $480 \pm 80$ d.C. & Llagostera et al. 1988 \\
& 8432 & $490 \pm 100$ d.C. & Nota 3 \\
& $"$ & $730 \pm 60$ d.C. & $"$ \\
Coyo Oriente & $930 \pm 80$ d.C. & $920 \pm 120$ d.C. & Berenguer et al. 1986 \\
Solcor 3 (fase B) & 1075 & $1085 \pm 100$ d.C. & UCTL 1488 \\
& 9085 & $510 \pm 150$ d.C. & Berenguer et al. 1986 \\
& tabletas tiwanaku & $570 \pm 60$ d.C. & Llagostera et al. 1988 \\
\hline
\end{tabular}


esta versión. En tanto, el patrón volumétrico se hace presente con ocho ejemplares; este es el que exhibe mayor variedad, acogiendo figuras antropomorfas, felinomorfas, falconimorfas y teratomorfas. El modo mixto se hace presente sólo en un felinomorfo duplo y en un reptilomorfo.

Los sitios que tienen mayor variedad de representaciones son Coyo Oriente, Quitor 5, Quitor 6 y Solcor 3 y los que menos, Quitor 2 y Séquitor Alambrado. En Quitor 5 hay tres casos de estilos que escapan de los clásicos (Figuras 2f, 7d y 10e), pero también en Coyo Oriente (Figuras $3 \mathrm{~b}$ y 7c) y Quitor 6 (Figura 3a) hay algunos que se alejan bastante de la modalidad más generalizada. En cuanto a la asociación que pudiera existir entre representaciones y sitios se observan ciertas tendencias, que por su baja representación no nos parecen significativas, aunque se hace importante registrarlas a modo de inventario. En Coyo Oriente: presencia de antropomorfos con brazos extendidos portando cetros, antropomorfos con manos en el pecho, falconimorfos y teratomorfos, siendo extraña la ausencia de sacrificadores. En Quitor 5: presencia de cefalomorfos y sacrificadores. En Quitor 6: felinomorfos y sacrificadores teratomorfos. En Solcor 3: felinomorfos, camelidomorfos y sacrificadores.

Entre la iconografía complementaria representada por cabezas de felinos, aves y peces, la presencia simultánea en una tableta de dos o tres de estas especies resulta ser la configuración más común (15); pero también hay tabletas que tienen solo una especie (siete con solo felino, cuatro con peces y una con ave), y un caso que no tiene estos complementos. La cabeza humana, sin considerar la cabeza cercenada portada por los sacrificadores, se hace presente en cuatro casos en los tocados de sacrificadores y en los cetros de personajes antropomorfos. En los pedestales es la cabeza de felino la que tiene mayor presencia ( 21 casos), en tanto que peces y aves aparecen en minoría (cinco y dos casos). No se observa ninguna relación definida de esta iconografía con los personajes centrales, pudiéndose presentar todas o cualquiera de las situaciones precedentes en cada una de las categorías. Lo mismo sucede en relación a los sitios arqueológicos ya que no hemos podido establecer ningún tipo de tendencia de la iconografía complementaria que permita caracterizar a cada uno o alguno de los yacimientos considerados.

Con el material analizado no es posible establecer una secuencia cronológica de las represen- taciones y tampoco de la iconografía complementaria. Aunque en este sentido es interesante constatar que las tabletas reconocidas como tempranas (9082 y 18273) (Figuras 9a, 10e) presentan estilos bastante peculiares, apartados de lo que podríamos definir como clásico y ostentado por la mayoría de las tabletas. Especialmente la tableta 9082 nos recuerda la iconografía de las fases tempranas de Tiwanaku. En el otro extremo, la tardía tableta 9085 (Figura 10c) se nos presenta como una magistral síntesis del arte clásico tiwanakota.

El estudio de Agüero et al. (2003) nos permite efectuar un análisis comparativo entre las tabletas de SPA y la litoescultura de Tiwanaku. Comenzando por la representación que pareciera ser la más importante de todas -el "Personaje Frontal"-el que aparece centralmente dispuesto en la iconografía de casi toda la variada gama de obras escultóricas Tiwanaku. A diferencia del Personaje Frontal presente en la litoescultura, el que siempre luce un tocado con una tupida orla de apéndices radiales, los personajes de las tabletas carecen de este tocado, a excepción del simplificado personaje de la tableta 14666, que presenta cuatro apéndices. En la litoescultura no existe el personaje con manos sobre el pecho, a excepción de los entes monolíti$\cos$, que teniendo las manos aproximadamente en esa posición, sostienen algunos objetos (tableta, vaso-kero) (Berenguer 1998).

Entre los "Personajes de Perfil", los antropomorfos-felinos que muestran los colmillos se hacen presentes tanto en la litoescultura como en las tabletas; pero es necesario destacar que no aparecen entre los entes monolíticos de Tiwanaku ni tampoco en la Puerta del Sol, sino solamente en los arquitrabes de Kantatayita y de Linares. Por su parte, los antropomorfos-ave (con rostro humano y ala) y los ornitomorfos-humanos (con cabeza de ave), populares en los soportes líticos, no están representados en las tabletas. Resulta entonces que justamente aquellos personajes más emblemáticos de Tiwanaku como son los que flanquean la figura central de la Puerta del Sol -el ave-antropomorfizada y el hombre alado- no aparecen en las tabletas.

La otra representación de Agüero et al. (2003), "Rostro Frontal", se asimila a nuestros cefalomorfos, presente repetitivamente en lo que estos autores llaman "Banda-faja" o complementaria. En las tabletas, en cambio, aparecen como una entidad en sí misma, más cuando una de ellas (9119) se le representa con cetros, considerados símbolos de 
jerarquía. Entre las figuras que se asocian a los Rostros Frontales de la litoescultura se describe "una pequeña plataforma escalonada y otra figura inscrita en su centro" y, como "complementos del tocado", se dice que presentan cabezas de ave y pez. En esto hay coincidencia como concepto iconográfico general, a excepción del ejemplar 9083 que llega a la máxima simplificación.

Llama la atención la escasa representación del camélido en las esculturas litoemblemáticas de Tiwanaku. Solamente aparece representado, en forma minoritaria y secundaria, en el monolito Bennett. Tampoco hay referencias al felino-ornitomorfo ni al reptil con pabellones auditivos.

En general se aprecia que en la litoescultura de Tiwanaku hay una evidente preferencia por la antropomorfización, la que va desde la figura humana pura hasta figuras teratomorfas con predominio de la fracción antropomorfa, híbridas con felinos o cóndor, pero no aparecen felinos ni cóndores en su versión normal o pura, y el camélido, como vimos, es incorporado excepcionalmente.

Proyectando la contextualización espacial y temporal al ámbito mayor de los Andes centro sur, hemos intentado relacionar la secuencia local con la secuencia construida para la litoescultura del centro de Tiwanaku. Para ello seguimos la propuesta de Agüero et al. (2003), quienes definen cinco fases que, sin embargo, no relacionan con parámetros cronológicos. Para ellos el Personaje Frontal aparece en la fase II y mantiene los pies en posición de perfil hasta la fase $\mathrm{V}$, donde estos giran hacia el frente. Si esta conjetura es cierta, las tabletas con personajes frontales de SPA serían asignables a la fase $\mathrm{V}$, dado que todos ellos presentan los pies de frente. Consecuentemente, pudieron llegar a SPA durante dicha fase. Los Personajes de Perfil con colmillos entrecruzados, hacha y cabeza cortada, según la mencionada secuencia correspondería a la fase I; en la fase II desaparecen el hacha y la cabeza cortada y en la fase III, desaparecen los colmillos. Según esto, las tabletas 8432, 9084 y 9110 (Figuras 11a, b, e) corresponderían a la fase I, la 9116 (Figura 11d) a la fase II y la 9117 (Figura 11c) a la fase III. Por su parte, las tabletas con Rostros Frontales se asimilarían con la fases III y siguientes.

Aunque las tabletas tiwanaku habrían llegado a SPA desde los primeros momentos en que esta iconografía aparece en el núcleo altiplánico, llama la atención la ausencia de Personajes Frontales con pies lateralizados, es decir, anteriores a la fase $\mathrm{V}$.

Tanto la riqueza expresiva del arte tiwanaku de su centro de origen como la creatividad sincrética de las localidades periféricas generaron, indudablemente, cantidades de tabletas dentro de una riquísima gama de estilos en un extenso territorio. Lamentablemente, por razones de preservación existen pocas tabletas tiwanaku en el ámbito circumpuneño, lo que dificulta la posibilidad de disponer de referentes comparativos para nuestra colección y poder asignar procedencias.

Otro aspecto a considerar es el hecho de que éstas no son las únicas tabletas del período Medio en SPA. En la Tabla 4 se puede apreciar que, en relación al universo de tabletas de este período, las tiwanakotas ocupan un bajo porcentaje $(17,5 \%)$, lo que indica que la mayor cantidad de tabletas contemporáneas con Tiwanaku $(82,5 \%)$ no estaban relacionadas con esta entidad.

Tabla 4. Relación de tabletas no-Tiwanaku y tabletas Tiwanaku en las tumbas del período Medio (fase Coyo) de los sitios de San Pedro de Atacama.

Relationship of non-Tiwanaku tablets and Tiwanaku tablets in the tombs of the Middle Period (Phase Coyo) from the sites of San Pedro de Atacama.

\begin{tabular}{lccccc}
\hline Tabletas & \multicolumn{2}{c}{ No Tiwanaku } & \multicolumn{2}{c}{ Tiwanaku } \\
Sitios & Cantidad & $\%$ & Cantidad & $\%$ & Total \\
\hline Quitor 2 & 2 & 50 & 2 & 50 & 4 \\
Quitor 5 & 23 & 79,9 & 7 & 20,6 & 29 \\
Quitor 6 & 44 & 86,2 & 2 & 13,7 & 51 \\
Sq.Al.Or & 12 & 85,7 & - & 14,2 & 14 \\
Sq.Al.Occ & - & 100 & 12 & - & 4 \\
Toconao Or. & 4 & 84,2 & 5 & 15,7 & 76 \\
Coyo Or. & 64 & 68,7 & 34 & 31,2 & 16 \\
Solcor 3. & 11 & 82,5 & 17,5 & 194 \\
\hline Total & 160 & & & \\
\hline
\end{tabular}


En consecuencia, las referidas tabletas tiwanakotas se insertan en el contexto general de la diversidad de objetos foráneos presentes en SPA, incluyendo la presencia de otros objetos tiwanaku, además de aquellos de otras filiaciones (p.ej. Aguada) (Llagostera 1995). En los contextos arqueológicos de SPA, desde tiempos tempranos y a lo largo de toda la época precolombina, se encuentran artefactos foráneos provenientes de: San Francisco, Chichas, Tupuraya, Chuquisaca, Lerma-Tarija, Mojocoya, Candelaria, Isla, Huruquilla-Yura, Tilcara-Yavi, Chilpe-Hedionda, etc. (ver Tarragó 1989). Las evidencias arqueológicas se- ñalan que en el formativo atacameño ya quedó estructurado un patrón político, social y cultural sui generis de integración e interacción puneña, el que acompañó a los atacameños en todo el transcurso de su desarrollo precolombino (Llagostera 1996).

Agradecimientos: Este trabajo hace parte del proyecto FONDECYT 1010735 “Tiwanaku en los oasis de San Pedro de Atacama: diversidad y desarrollo de sus manifestaciones". Investigador Responsable: Agustín Llagostera; Coinvestigadores: María Antonieta Costa y Carolina Agüero.

\section{Referencias Citadas}

Agüero, C., M. Uribe y J. Berenguer

2003 Iconografía Tiwanaku: El caso de la escultura lítica.

Textos Antropológicos 14:47-82.

Berenguer, J.

1998 La iconografía del poder en Tiwanaku y su rol en la integración de zonas de frontera. Boletín del Museo Chileno de Arte Precolombino 7:19-37.

Berenguer, J., A. Deza, A. Román y A. Llagostera

1986 La Secuencia de Myriam Tarragó para San Pedro de Atacama: Un test por termoluminiscencia. Revista Chilena de Antropología 5:17-54.

Cordy-Collins, A.

1979 Cotton and staff god: Analysis of an ancient Chavin textile. En The Junius B. Bird Precolumbian Textile Conference, editado por A. Pollard Rowe and L. Schaffer, pp. 51-60. The Textile Museum and Dumbarton Oaks, Washington, D.C.

Knobloch, P.J.

2000 Wari ritual power at Conchopata: An interpretation of Anadenanthera colubrina iconography. Latin American Antiquity 11:387-402.

Llagostera, A.

1992 Art in the snuff trays of San Pedro de Atacama (Northern Chile). En Andean Art: Visual Expression and its Relation to Andean Beliefs and Values, editado por P. Dransart, pp. 51-77. Worldwide Archaeology Series 13, Avebury. 1995 El componente Aguada en San Pedro de Atacama. Boletín del Museo Chileno de Arte Precolombino 6:9-34.

1996 San Pedro de Atacama: Nodo de complementariedad reticular. En La Integración Surandina Cinco Siglos Después. Estudios y Debates Regionales Andinos 91, pp. 1742. Centro de Estudios Regionales Andinos "Bartolomé de Las Casas". Cuzco.

2001 Archeologia degli allucinogeni in San Pedro de Atacama (Cile del Nord). Archeologia degli allucinogeni nelle Ande (Numero Speciale), editado por C.M. Torres y A. Llagostera. Eleusis 5:101-121.
Llagostera, A., C.M. Torres y M.A. Costa

1988 El complejo psicotrópico de Solcor-3 (San Pedro de Atacama). Estudios Atacameños 9:61-98.

Tarragó, M.N.

1968 Secuencias culturales de la etapa agroalfarera de San Pedro de Atacama (Chile). XXXVII Congreso Internacional de Americanistas Vol. II:119-144. Buenos Aires.

1989 Contribución al Conocimiento Arqueológico de las Poblaciones de los Oasis de San Pedro de Atacama en Relación con los otros Pueblos Puneños, en Especial, el Sector Septentrional del Valle Calchaquí. Tesis para optar al título de Doctor. Universidad Nacional de Rosario, Rosario.

Torres, C.M

1984 Iconografía de las tabletas para inhalar sustancias psicoactivas de la zona de San Pedro de Atacama, Norte de Chile. Estudios Atacameños 7:178-196.

1986 Tabletas para alucinógenos en Sudamérica: Tipología, distribución y rutas de difusión. Boletín del Museo Chileno de Arte Precolombino 1:37-53.

1987 The iconography of South American snuff trays and related paraphernalia. Göteborgs Etnografiska Museum Etnologiska Studier 37.

1998 Psychoactive substances in the archaeology of northern Chile and north-western Argentina. Chungara 30:49-63.

2001 Iconografía Tiwanaku en la parafernalia inhalatoria de los Andes Centro-Sur. Boletín de Arqueología PUCP 5:427-454.

2004 Imágenes legibles: La iconografía Tiwanaku como significante. Boletín del Museo Chileno de Arte Precolombino 9:55-73

Torres, C.M., D.B. Repke, K. Chan, D. Mackenna, A. Llagostera y R.E. Schultes

1991 Snuff powders from pre-hispanic San Pedro de Atacama: Chemical and contextual analysis. Current Anthropology 32:640-649. 
Uribe, M. y C. Agüero

2001 Alfarería, textiles y la integración del norte grande de Chile a Tiwanaku. Boletín de Arqueología PUCP 5:397-426. Urton, G.

1981 At the Crossroads of Earth and the Sky: An Andean Cosmology. University of Texas Press, Austin.
Yacovleff, E. y F.L. Herrera

1934-35 El Mundo vegetal de los antiguos peruanos. Revista del Museo Nacional, Tomo III, № 1-2, pp. 243-322. Ibid. Tomo IV, № 1, pp. 31-102. Lima.

\section{Notas}

1 Para hacer referencia a los ejemplares de tabletas se ha utilizado el número del catálogo de la colección del Museo "R.P. Gustavo Le Paige s.j.".

2 Interpretado como representación de Anadenanthera colubrina (Knobloch 2000).
3 El rango cronológico postulado por Berenguer y colaboradores (1986) para la Fase Coyo iría de 700 a 1.000 d.C. Recientes fechas TL obtenidas por nosotros para el sitio Coyo Oriente podrían proyectar esta fase hasta 1.080-1.230 d.C. Este es un tema que requiere seguir siendo trabajado. 
